\title{
Visual Rating and the Use of Image Analysis for Assessing Different Symptoms of Citrus Canker on Grapefruit Leaves
}

\author{
C. H. Bock, University of Florida/USDA, 2001 S. Rock Rd., Ft. Pierce, FL 34945; P. E. Parker and A. Z. Cook, \\ USDA-APHIS-PPQ, Moore Air Base, Edinburg, TX 78539; and T. R. Gottwald, USDA-ARS-USHRL, 2001 S. \\ Rock Rd., Ft. Pierce, FL 34945
}

\begin{abstract}
Bock, C. H., Parker, P. E., Cook, A. Z., and Gottwald, T. R. 2008. Visual rating and the use of image analysis for assessing different symptoms of citrus canker on grapefruit leaves. Plant Dis. 92:530-541.

Citrus canker is caused by the bacterial pathogen Xanthomonas axonopodis pv. citri and infects several citrus species in wet tropical and subtropical citrus growing regions. Accurate, precise, and reproducible disease assessment is needed for monitoring epidemics and disease response in breeding material. The objective of this study was to assess reproducibility of image analysis (IA) for measuring severity of canker symptoms and to compare this to visual assessments made by three visual raters (VR1-3) for various symptom types (lesion numbers, $\%$ area necrotic, and $\%$ area necrotic+chlorotic), and to assess inter- and intra-VR reproducibility. Digital images of 210 citrus leaves with a range of symptom severity were assessed on two separate occasions. IA was more precise than VRs for all symptom types (inter-assessment correlation coefficients, $r$, for lesion numbers by IA $=0.99$, by VRs $=0.89$ to 0.94 ; for $\%, r$ for $\%$ area necrotic + chlorotic for IA $=0.97$ and for VRs $=0.86$ to 0.89 ; and $r$ for $\%$ area necrotic for IA $=0.96$ and for VRs $=$ 0.74 to 0.85 ). Accuracy based on Lin's concordance coefficient also followed a similar pattern, with IA being most consistently accurate for all symptom types (bias correction factor, $C_{b}=0.99$ to 1.00$)$ compared to visual raters $\left(C_{b}=0.85\right.$ to 1.00$)$. Lesion number was the most reproducible symptom assessment (Lin's concordance correlation coefficient, $\rho_{\mathrm{c}},=0.76$ to 0.99 ), followed by $\%$ area necrotic+chlorotic ( $\rho_{c}=0.85$ to 0.97$)$, and finally $\%$ area necrotic $\left(\rho_{c}=0.72\right.$ to 0.96$)$. Based on the "true" value provided by IA, precision among VRs was reasonable for number of lesions per leaf $(r=0.88$ to 0.94$)$, slightly less precision for $\%$ area necrotic+chlorotic $(r=0.87$ to 0.92$)$, and poorest precision for $\%$ area necrotic $(r=0.77$ to 0.83$)$. Loss in accuracy was less, but showed a similar trend with counts of lesion numbers $\left(C_{b}=0.93\right.$ to 0.99$)$ which was more consistently accurately reproduced by VRs than either \% area necrotic $\left(C_{b}=0.85\right.$ to 0.99$)$ or $\%$ area necrotic+chlorotic $\left(C_{b}=0.91\right.$ to 1.00$)$. Thus, visual raters suffered losses in both precision and accuracy, with loss in precision estimating $\%$ area necrotic being the greatest. Indeed, only for $\%$ area necrotic was there a significant effect of rater (a two-way random effects model ANOVA returned a $P<0.001$ and 0.016 for rater in assessments 1 and 2 , respectively). VRs showed a marked preference for clustering of $\%$ area severity estimates, especially at severity $>20 \%$ area (e.g., 25, 30, 35, 40, etc.), yet VRs were prepared to estimate disease of $<1 \%$ area, and at $1 \%$ increments up to $20 \%$. There was a linear relationship between actual disease (IA assessments) and VRs. IA appears to provide a highly reproducible way to assess canker-infected leaves for disease, but symptom characters (symptom heterogeneity, coalescence of lesions) could lead to discrepancies in results, and full automation of the system remains to be tested.
\end{abstract}

Additional keywords: disease incidence, disease intensity, epidemiology, infection

Citrus canker, a disease affecting the majority of commercial citrus species and cultivars, is caused by the bacterial pathogen Xanthomonas axonopodis pv. citri. The disease is of particular concern in wet tropical and subtropical citrus growing regions where infection occurs as a result of rain splash $(5,6,37)$ and causes yield

Corresponding author: Clive Bock

E-mail: clive.bock@ars.usda.gov

Accepted for publication 8 November 2007.

doi:10.1094/PDIS-92-4-0530

This article is in the public domain and not copyrightable. It may be freely reprinted with customary crediting of the source. The American Phytopathological Society, 2008. loss and severely blemished fruit, which are unsuitable for the fresh market (38). In Florida, subsequent to the termination of the Citrus Canker Eradication Program early in 2006 (13), new ways of managing the disease are being sought and disease assessment procedures are an important component of various research trials. The importance of good quality disease assessment has been previously discussed $(7,22,32,39)$. Accurate, precise, and reproducible assessment of canker symptoms is needed in estimating incidence and severity of infection, and is of particular importance for monitoring epidemics, resistance screening, and assessing the effect of disease on yield, particularly fruit number and size (as opposed to the important but related aspect of reduced aesthetic value of diseased fruit; 38).

Citrus canker symptoms on leaves are somewhat complex and change as the infection progresses over a period of several weeks $(9,21,38)$. Lesions age and change in color, texture, and size from a small, water-soaked, pin-prick-sized lesion to a larger lesion ( 3 to $5 \mathrm{~mm}$ ) with a chlorotic halo and necrotic center. Finally, they senesce to patches of necrotic tissue on a leaf, and may eventually lead to shot-holing of older leaves. Apart from incidence (number of plant units infected) and severity score (area infected), on individual organs the actual number of infection sites can be of interest (especially for epidemiological studies and plant breeding endeavors), and can be assumed to equate to lesion number, since as little as one or two bacteria can cause infection (12). However, it is not known how lesion number relates to leaf area displaying symptoms, although it has been established that incidence of infected trees is highly correlated with severity of infection in the $X$. axonopodis pv. citri-citrus pathosystem (1). How effectively raters count lesion numbers does not appear to have been estimated for any pathosystem, and estimates of areas covered by symptoms has not been established for citrus canker, although accuracy and precision data are available for other diseases where diseased area has been estimated (28,31). Furthermore, an understanding of the symptoms and the relationships among them should help ascertain which to choose for specific purposes. For example, relationships between yield and percent area with symptoms may result in a more meaningful relationship than with number of lesions (infection sites).

Several techniques are available to measure disease apart from direct visual rating (VR), including radiometry $(27,31)$ and image analysis (IA, 25,27). Estimates of disease by IA have been compared to those obtained by trained plant pathologists for assessing the severity of infection and found to provide good, repeatable estimates of disease in many cases $(8,25,26)$, although there are some examples where IA has resulted in relatively poor assessment $(31,34)$. Interestingly, even where IA parameters were set prior to analyzing a batch of leaves, some studies returned poor results (34), whereas others returned highly reproducible results (26). The char- 
acteristics of some diseases might predispose them to relatively easy digital demarcation of healthy-diseased borders, and others may not. VR is the only method of disease assessment that has been used to assess citrus canker, and IA has the potential to perform more reproducible estimates of area covered by symptoms on a leaf, plant, or in a crop $(25,26)$. Once established as a reliable "true" value of "actual" disease, IA (or other accurate, precise, and reproducible systems) can be used to form the basis for testing rater abilities $(28,31,39)$, although even the "truest" true value will be anthropically biased at some point in the disease delineation process. No tests have been performed on symptoms of citrus canker to establish how well they are rated by VRs or IA.

Various scales have been developed for visually assessing disease severity, including the widely adopted Horsfall-Barratt (HB) scale (16-18), which is based on the nonexistent Weber-Fechner law which stated "visual acuity depends on the log of the intensity of the stimulus". The WeberFechner law is actually comprised of two laws, Weber's Law and Fechner's Law $(3,29,42)$. Weber's Law states the ratio of the increment threshold to the background intensity is a constant, whereas Fechner's Law (based on theoretical assumptions) states the observer response is related to the logarithm of the stimulus intensity (3). Fechner's Law has been questioned $(3,41,42)$. Indeed, if the relationship between actual and perceived disease was logarithmic, we should expect to see this in various empirical studies. However, reports have shown the relationship to be generally linear (11,26,28,31,39). In addition, studies on the basis of threshold perception also suggest that severities of 25,37 , and $50 \%$ are perceived with similar ability (29), although lower (and higher) severities have not been tested. The HB scale (and similar scales) has clung on in plant pathology, although the scales may be abrogated by an empirical approach to testing the rela-

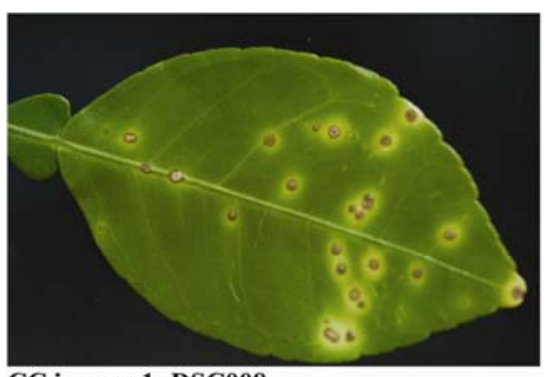

CC images 1: DSC008

Number of lesions:

$\%$ area covered by necrotic area only:

$\%$ area covered by necrotic + chlorotic area:

Fig. 1. Typical image of a grapefruit leaf assessed by image analysis and three visual raters for number of lesions of citrus canker, \% leaf area necrotic, and \% leaf area necrotic+chlorotic due to symptoms of citrus canker. tionship between actual disease and perceived disease $(15,28,29,33)$. Nonetheless, the HB scale still forms the basis of studies, and the rationale of the Weber-Fechner law has been recently applied to the development of a set of assessment cards for citrus canker (4). However, there is also evidence in several studies that variance of the estimate at lower ( $<25 \%$ disease) or higher $(>75 \%$ disease) severity may be lower $(10,20)$, and that raters may prefer particular disease ratings, or "knots" with estimates to the nearest $5 \%$ severity favored in the midrange $(20,39)$. Evidence suggests that the HB scale does not appear to offer an advantage over direct estimation (best guess, aided or unaided by disease assessment cards) of disease by VRs (28). Based on these observations, we chose to estimate disease on a continuous scale (0 to $100 \%$ ) when performing visual estimates, rather than using a predetermined scale.

The objectives of this study were the following: (i) to investigate the accuracy, precision, and reproducibility of IA and VR for assessing different symptom types of citrus canker; (ii) to compare how VRs (all experienced plant pathologists) vary in estimating different symptom types of citrus canker; and (iii) to identify the relationship between observed (VR) and actual (IA) citrus canker severity.

\section{MATERIALS AND METHODS}

Leaves and leaf images. Leaves were collected from naturally infected Ruby red grapefruit trees in Dade County, Miami,
FL. The leaves were chosen arbitrarily, but to reflect the approximate frequency and range of citrus canker severities available at the time. A few disease-free leaves were also included. Leaf miner infested or incomplete leaves were not used. A total of 210 leaves were photographed using two different cameras: a 6.5 megapixel Canon EOS 10D (24 to $85 \mathrm{~mm}$ AF lens) and a 1.6 megapixel Sony FD Mavica. Image size was standardized and printed (3.25 in. $\times$ 2.25 in.) and approximately reflected the size of the leaf, with six images per page. The 210 digital images were all assessed twice, with a period of at least 8 months between the first and second assessments, both visually and using IA for lesion number, \% area necrotic, and \% area necrotic+chlorotic (Fig. 1). The repeat assessment allowed identification of within rater/method reproducibility, and multiple VRs allowed investigation of inter- and intra-rater reliability and determination whether raters assessed different symptom components with equal levels of precision and accuracy.

Visual assessments. Each image was visually assessed by three plant pathologists (VR1-3). Assessments were made independently with rest periods taken at the discretion of the individual raters. Based on results of various studies $(11,15,28,29,39)$, we chose direct estimation of disease severity (percent area) for the visual assessments over a disease scale approach.

Image analysis. The image analysis software Assess (American Phytopath-

Table 1. The mean, range, and standard deviation of estimates of number of lesions of citrus canker, $\%$ leaf area necrotic, and \% leaf area necrotic+chlorotic infected with citrus canker for 210 grapefruit leaves assessed by image analysis and three visual raters on two separate occasions

\begin{tabular}{|c|c|c|c|c|}
\hline $\begin{array}{l}\text { Variable } \\
\text { Assessment }\end{array}$ & Assessment type & Mean & Range & $\begin{array}{l}\text { Standard } \\
\text { deviation }\end{array}$ \\
\hline \multicolumn{5}{|l|}{ Lesion number } \\
\hline \multirow[t]{4}{*}{ Assessment 1} & Image analysis & 17.9 & $0-120$ & 22.9 \\
\hline & Rater 1 & 17.9 & $0-128$ & 24.0 \\
\hline & Rater 2 & 18.0 & $0-145$ & 24.8 \\
\hline & Rater 3 & 16.2 & $0-150$ & 19.4 \\
\hline \multirow{4}{*}{ Assessment 2} & Image analysis & 18.0 & $0-127$ & 23.0 \\
\hline & Rater 1 & 18.8 & $0-264$ & 29.4 \\
\hline & Rater 2 & 17.9 & $0-123$ & 24.4 \\
\hline & Rater 3 & 22.8 & $0-154$ & 32.6 \\
\hline \multicolumn{5}{|l|}{$\%$ area necrotic } \\
\hline \multirow[t]{4}{*}{ Assessment 1} & Image analysis & 3.3 & $0-18.5$ & 3.5 \\
\hline & Rater 1 & 3.5 & $0-20.0$ & 3.1 \\
\hline & Rater 2 & 5.2 & $0-20.0$ & 4.8 \\
\hline & Rater 3 & 5.3 & $0-30.0$ & 5.1 \\
\hline \multirow[t]{4}{*}{ Assessment 2} & Image analysis & 3.4 & $0-21.2$ & 3.7 \\
\hline & Rater 1 & 4.1 & $0-15.0$ & 2.9 \\
\hline & Rater 2 & 4.8 & $0-35.0$ & 5.1 \\
\hline & Rater 3 & 4.6 & $0-25.0$ & 3.9 \\
\hline \multicolumn{5}{|c|}{$\%$ area necrotic+chlorotic } \\
\hline \multirow[t]{4}{*}{ Assessment 1} & Image analysis & 9.1 & $0-58.8$ & 10.0 \\
\hline & Rater 1 & 10.6 & $0-75.0$ & 12.9 \\
\hline & Rater 2 & 8.7 & $0-50.0$ & 8.4 \\
\hline & Rater 3 & 10.6 & $0-70.0$ & 11.8 \\
\hline \multirow[t]{4}{*}{ Assessment 2} & Image analysis & 8.8 & $0-58.8$ & 9.7 \\
\hline & Rater 1 & 8.9 & $0-65.0$ & 9.7 \\
\hline & Rater 2 & 7.5 & $0-70.0$ & 9.5 \\
\hline & Rater 3 & 12.5 & $0-75.0$ & 13.1 \\
\hline
\end{tabular}


ological Society, St. Paul, MN) was used to count lesion number and measure area displaying necrosis and necrosis+chlorosis (35). Each image was sized to approximately $1,000 \times 600$ pixels at a resolution of 300 pixels per inch using the image editing software, allowing a view of the entire leaf surface to perform analyses. Studies have shown that images with as few as 858 pixels per image ( $c f .600,000$ in the current study) are sufficient for accurate reproduction of actual diseased areas-there is no advantage to greater resolution (40). Each leaf image on each of the two assessment occasions was outlined by hand in Assess to separate it from the background, the leaf being separated from the background by applying an overlay, which gives a clear view of the selected area. A histogram reveals the distribution of color in the pixels within the selected area of the image and allows choice of the correct settings to set the threshold for healthy leaf and lesion areas of the image. Once the leaf is selected, the program calculates the area in pixels and retains that value for subsequent measurements. The threshold was then set to select the color of the necrotic area in preparation to count the lesions. Where lesions coalesced, separation was achieved using two functions. The automatic separation function (watershed segmentation) was applied, and where this did not work, a manual separation function was used to draw a boundary between the lesions. The percent area function was then applied and the color images measured for the necrotic+ chlorotic area, the overlay being set to outline and the thumbnails (the program controls that determine the color range to be selected) adjusted until the best fit of the chlorosis/necrosis is selected. The thumbnail settings for the leaf and lesion

\section{Assessment 1}
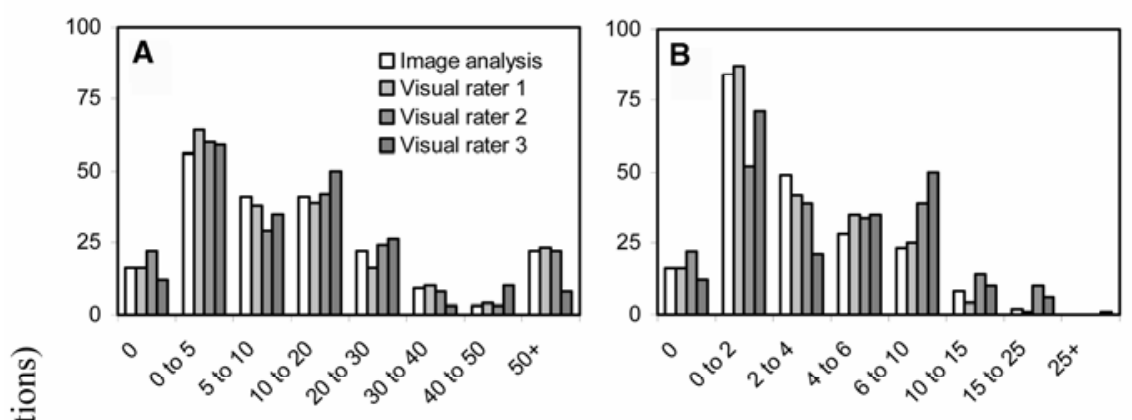

Range category - number of lesions
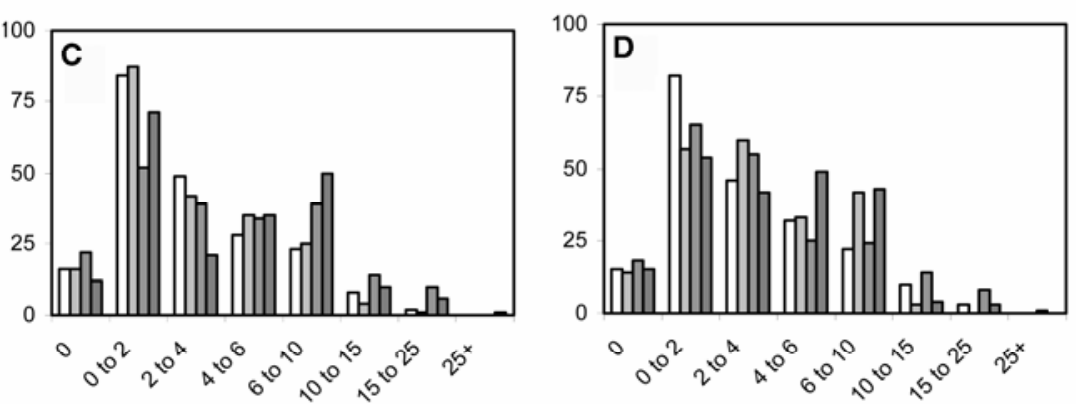

Range category $-\%$ area necrotic
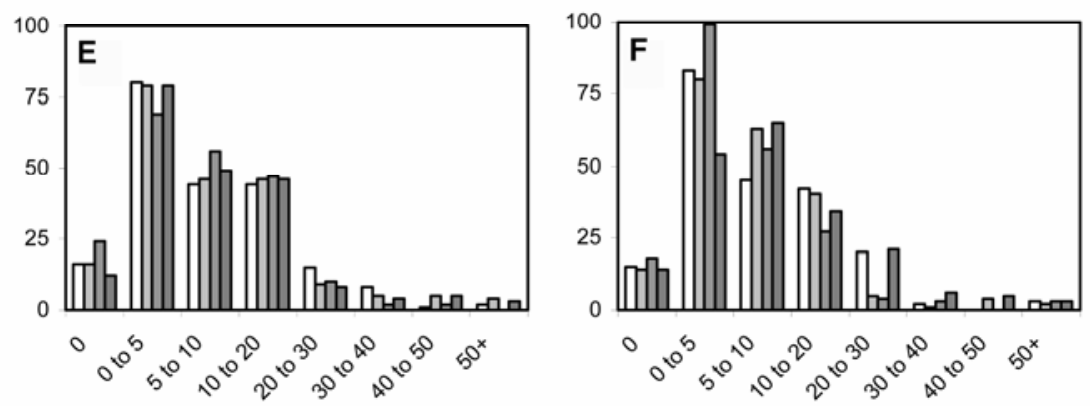

Range category $-\%$ area necrotic + chlorotic

Fig. 2. The frequency of estimates of lesion numbers (A and B), \% leaf area necrotic (C and D), and $\%$ leaf area necrotic+chlorotic (E and F) for citrus canker symptoms on 210 grapefruit leaves assessed on two different assessment occasions by image analysis and three visual raters. are retained by Assess, providing a guideline for the subsequent image measurements. Some image enhancement was necessary to optimize measurements because of inconsistency in lighting among images, slight differences in the color of healthy leaf tissue, and variation in necrosis color. Additionally, there are filters, contrast and color saturation functions, and color balancers within the Assess program. These are applied on a case by case basis and were used to consistently enhance the entire area of interest to maintain measurement accuracy.

Data analysis. Both precision and accuracy of the disease assessments were investigated. Sensu Campbell and Madden (7), accuracy is the closeness of a sample estimate to the actual value, and precision is considered to be the repeatability or variation associated with an estimate. The reproducibility of an assessment is the ability of the rater or disease assessment system to repeat a prior assessment both accurately and precisely.

Correlation analysis was used to measure the degree of association among raters, methods, and repetitions (32). The Pearson's correlation coefficient $(r)$ was calculated using PROC CORR in SAS (SAS Systems, Cary, NC) and indicates precision of the linear relationship between the two variables. Inter-rater reliability was further assessed using two-way random effects ANOVA (PROC ANOVA) as described by Nita et al. (28). Data were transformed to stabilize the heterogeneity of variance and preclude violation of any assumptions in the analysis (lesion number was $\log$ transformed and \% area estimates were transformed using the angular transformation). The intra-class correlation coefficient $(\rho)$ was calculated using the different variance components from the ANOVA $\left(\rho_{\text {leaf }}^{2} \rho_{\text {rater, }}^{2} \rho_{\text {error }}^{2}\right): \quad \rho=$ $\rho_{\text {leaf }}^{2} /\left(\rho_{\text {leaf }}^{2}+\rho_{\text {rater }}^{2}+\rho_{\text {error }}^{2}\right)$. For each run of the experiment, a separate analysis was performed.

The inter- and intra-rater/method relationships were also explored using linear regression analysis (PROC REG) to compare the reproducibility of repeat assessments by both methods (image analysis and visual raters) and to compare image analysis to visual raters. Regression analysis has previously been used to assess reproducibility of disease assessment, and various statistics can be used to characterize the agreement $(31,32)$. The slope, intercept, and associated standard errors were calculated and are shown. If slope $=1$ and intercept $=0$, the assessment is accurate, and deviation of slope and intercept from expected values can indicate bias and loss in precision and/or accuracy $(22,30,31)$. However, significant differences in intercept and slope can be highly dependent on the scatter (precision) of points and magnitude of the residual error (23), so due to their potentially misleading nature we have 
chosen not to interpret them; instead Lin's concordance correlation coefficient is calculated to explore accuracy and its relationship to precision (see below). Coefficients of determination $\left(r^{2}\right)$ were calculated for each regression solution to test the goodness of fit, and equate to the squared value of the correlation coefficient, but provide a more useful estimate of the proportion of overlapping variance between the two data sets (how much $X$ explains $Y$ ), or the degree to which the two data sets vary. The coefficient of variation $(\mathrm{CV})$ is also calculated and gives a measure of precision providing a standardized estimate of the amount of error associated with the sample $(7,32)$ :

$$
C V=(\sqrt{M S E / \bar{x}}) \times 100
$$

where MSE is the mean square error and $\bar{x}$ is the mean for the sample. The standard error of the $Y$-estimate was also calculated to indicate precision (32). The standard error of the estimate offers additional information beyond the $C V$ as it indicates the error involved in the actual prediction, compared to the overall error indicated by the $C V$. The standard error of the estimate $\left(\sigma_{\text {ypred }}\right)$ is calculated:

$$
\sigma_{\text {ypred }}=\sigma_{y} \sqrt{1-r^{2}}
$$

where $\sigma_{y}$ is the standard deviation of the dependent variable $Y$, and $r$ is the correlation coefficient between $X$ and $Y$.

Lin's concordance correlation coefficient $(23,24,28)$ provides an unbiased and quantifiable method to test reproducibility. It calculates and evaluates the degree to which pairs of observations fall on the concordance line of $45^{\circ}$ (slope $=1$, intercept $=0$ ), and the concordance correlation coefficient $\rho_{c}$ combines the two measures to assess relational fit to the notional $45^{\circ}$ perfect relation and is calculated as:

$$
\rho_{c}=\rho C_{b}
$$

where $C_{b}$ is a bias correction factor that measures how far the best-fit line deviates from $45^{\circ}$ and is thus a measure of accuracy, and $r$, the previously described correlation coefficient between $X$ and $Y$, measures the precision of the best-fit line. $C_{b}$, the bias correction factor, is derived from:

$$
C_{b}=\left[\left(v+1 / v+\mu^{2}\right) / 2\right]^{-1}
$$

where $v=\sigma_{x} / \sigma_{y}$ and $u=\left(\mu_{x}-\mu_{y}\right) / \sqrt{\sigma_{x} \sigma_{y}}$

The coefficient $v$ defines the scale, or slope, shift $(1=$ perfect relation between $X$ and $Y$ ), and $\mu$ is the location, or height, shift relative to the perfect relation $(0=$ perfect relation between $X$ and $Y$ ). Other symbols are defined as already described.

Finally, the two assessments by each visual rater (VR1-3) and each type of symptom were compared by testing for heterogeneity of regression between assessments using general linear modeling, GLM (PROC GLM), testing for both slope and intercept differences.

\section{RESULTS}

General. The range of lesion numbers, severity estimates, and associated mean values and standard deviations showed broad agreement among raters and between IA and VRs (Table 1). Lesion number estimated by IA ranged from 0 to 127 , and by the visual raters from 0 to 264 (Table 1). The count of 264 by VR1 was somewhat of an outlier, but checking the original data confirmed that this was in- deed the count by that rater. Disease severity (\% area necrotic) as assessed by IA ranged from 0 to 21.2, and by VRs from 0 to 35 , whereas the $\%$ area necrotic+ chlorotic ranged from 0 to 58.8 with IA, and from 0 to 75.0 with VRs. The frequency of lesion numbers and the $\%$ area infected (\% area necrotic and $\%$ area necrotic+chlorotic) in different category ranges as assessed by IA and VR1-3 appeared to show comparable distributions in both assessment 1 and 2 (Fig. 2A to $\mathrm{C}$ ).

Repeatability of assessments by IA and VRs. Correlation analysis (Table 2) showed image analysis to consistently have the greatest precision for lesion number, percent area necrotic, and percent area necrotic and chlorotic $(r=0.99,0.96$, and 0.97 , respectively). Correlation coefficients were consistently lower for all repeat assessments of VRs for lesion number $(r=$ 0.89 to 0.97$), \%$ area necrotic+chlorotic ( $r$ $=0.86-0.89)$, and $\%$ area necrotic, which showed the lowest precision $(r=0.74$ to $0.85)$. Similarly, the regression analysis (Table 2) showed the coefficient of determination $\left(r^{2}\right)$ was greatest for IA lesion numbers (assessments 1 and 2, $r^{2}=0.99$ ) compared to the VRs (assessments 1 and 2, $r^{2}=0.81$ to 0.94 ), and was more precise than assessments of \% area necrotic+ chlorotic (assessments 1 and $2, r^{2}=0.75$ to 0.95 ) and \% area necrotic (assessments 1 and $2, r^{2}=0.55$ to 0.93$)$. The $C V$ conformed to the same pattern: IA had the lowest $C V$ between the two assessments for lesion number, $\%$ area necrotic, and \% area necrotic+chlorotic $(C V=14.1,25.4$, and 28.6, respectively). The standard error of the prediction also showed that the estimate was more repeatable for IA than for VRs, with the standard error of the prediction being at least two or more times greater for the VRs compared to the IA

Table 2. Linear regression analysis ${ }^{\mathrm{a}}$ between the first and second assessments of citrus canker symptom estimates by image analysis and three visual raters for number of lesions, \% leaf area necrotic, and \% leaf area necrotic+chlorotic

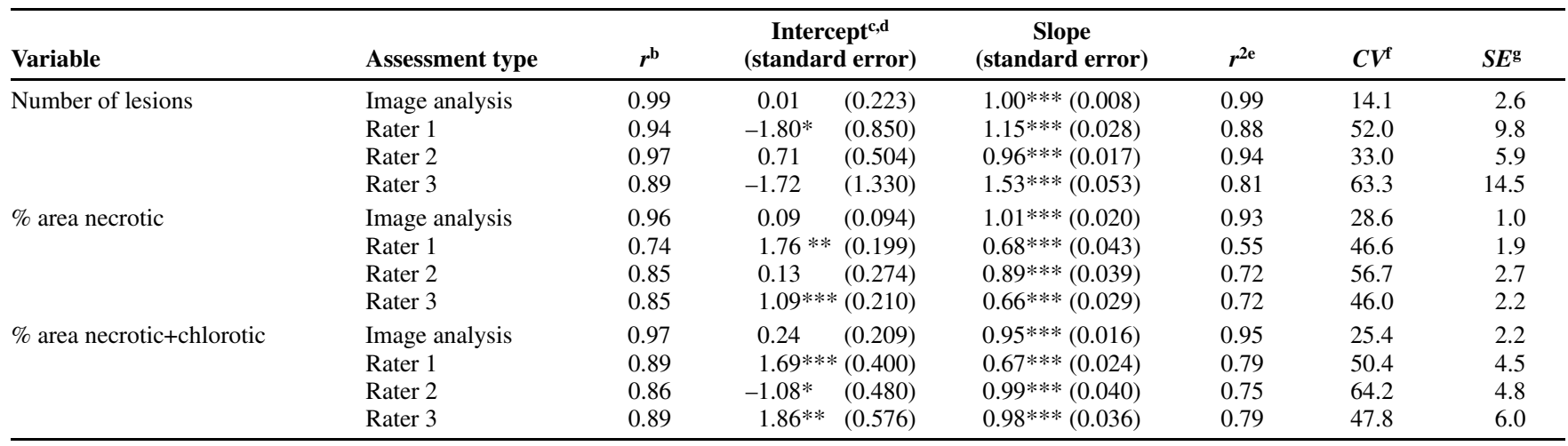

${ }^{a}$ Linear regression analysis model $y=a+b x$, where $a=$ intercept, and $b=$ slope.

${ }^{\mathrm{b}}$ Correlation coefficient measures the degree of association between raters.

c $*, * *, * * *$, Probability $=0.05,0.01$, and 0.001 , respectively.

${ }^{\mathrm{d}}$ Significant deviation of the intercept from 0 indicates a positive or negative over- or under-estimate of the value, constituting a constant systematic error; significant deviation of the slope from 1.0 indicates proportional systematic error between assessments.

${ }^{\mathrm{e}}$ Coefficient of determination is a quantitative measure of precision (or agreement) between the two assessments-the degree to which the X-data explain the Y-data.

${ }^{\mathrm{f}}$ Coefficient of variation is a measure of repeatability (precision).

$\mathrm{g}$ Standard error of the estimate provides a measure of the difference between assessments, quantifying the random error. 

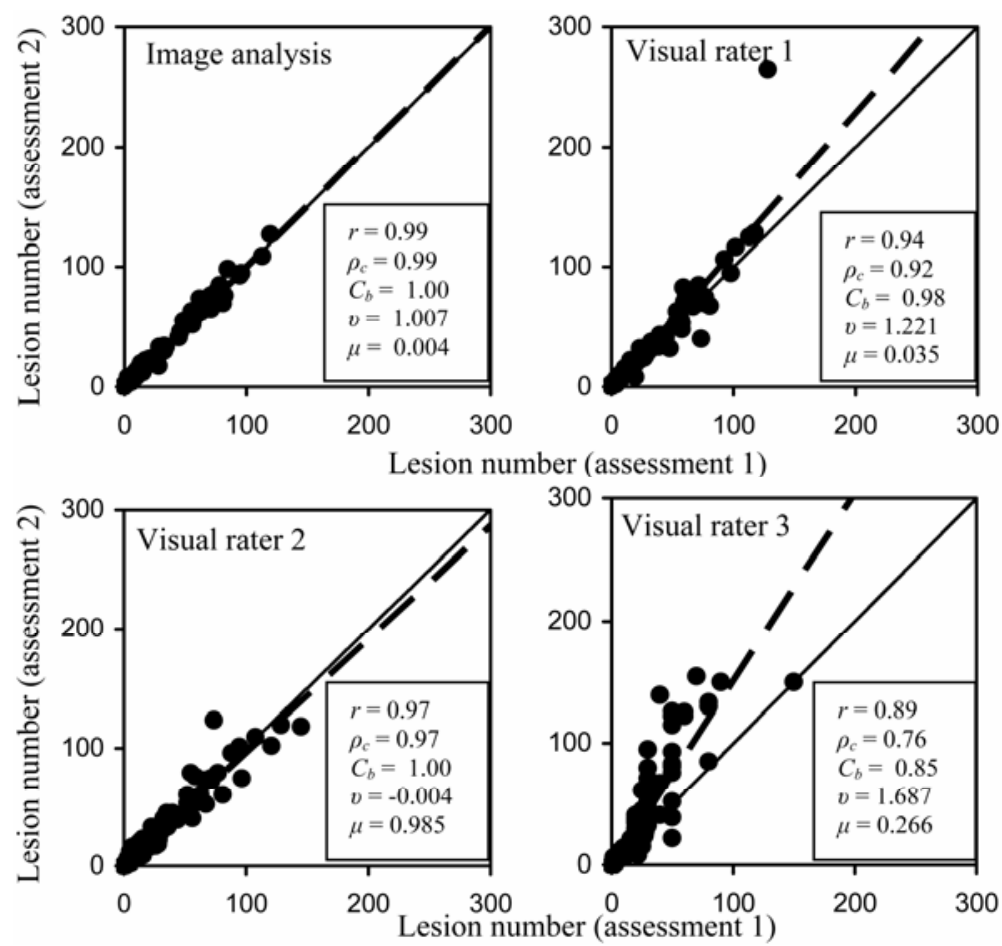

Fig. 3. A comparison of the number of lesions of citrus canker estimated on two separate assessment dates by image analysis and three visual raters. The concordance line is indicated by the solid line, and the broken line shows the actual relationship between the two assessments. Both measures of accuracy and precision are presented. The correlation coefficient, $r$, provides a measure of precision, and Lin's concordance correlation $\left(\rho_{c}\right)$ combines measures of precision $(r)$ and accuracy $\left(C_{b}\right)$, which is dependent on scale, or slope shift $(v, 1=$ no bias between $X$ and $Y$ ), and location, or height shift $(\mu, 0=$ no bias) relative to the concordance line.
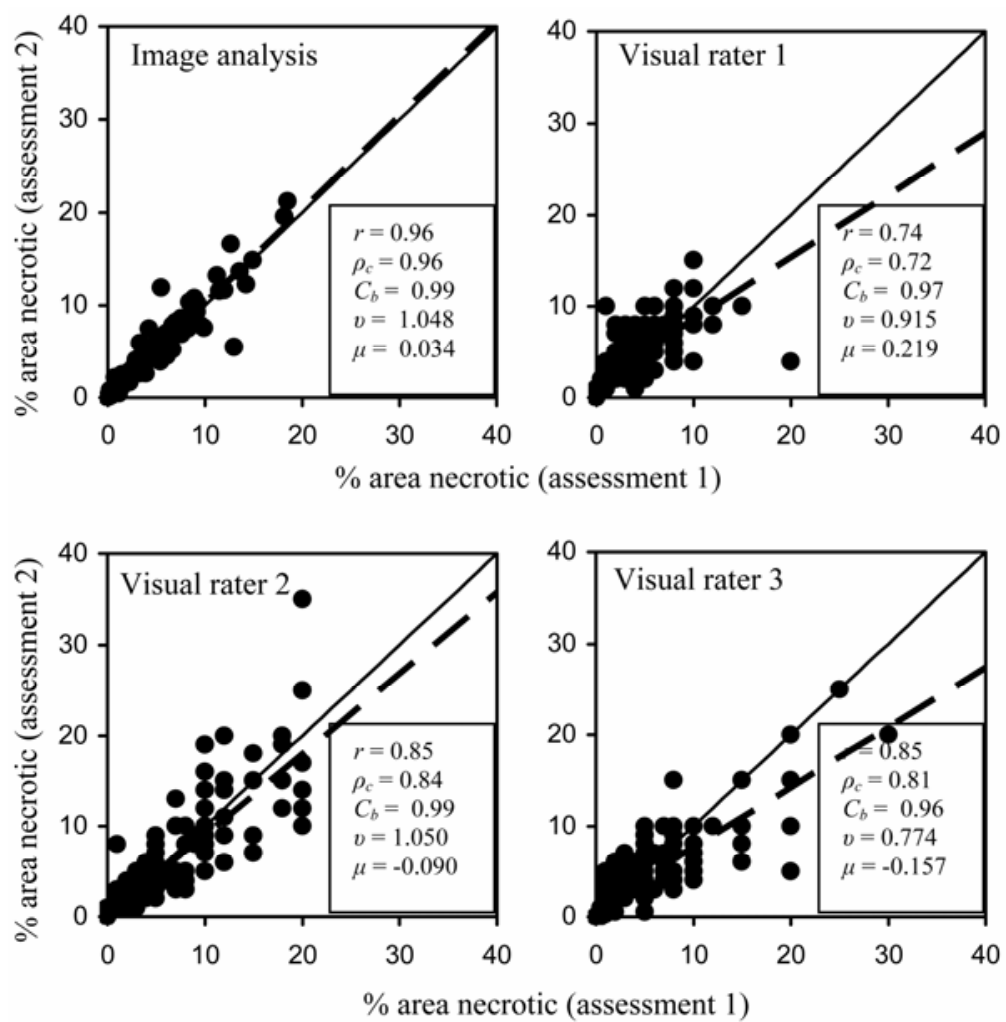

Fig. 4. A comparison of the $\%$ area necrotic due to symptoms of citrus canker estimated on two separate assessment dates by image analysis and three visual raters. The concordance line is indicated by the solid line, and the broken line shows the actual relationship between the two assessments. Both measures of accuracy and precision are presented. The correlation coefficient, $r$, provides a measure of precision, and Lin's concordance correlation $\left(\rho_{c}\right)$ combines measures of precision $(r)$ and accuracy $\left(C_{b}\right)$, which is dependent on scale, or slope shift $(v, 1=$ no bias between $X$ and $Y)$, and location, or height shift $(\mu, 0=$ no bias) relative to the concordance line. estimate for lesion number, \% area necrotic, and \% area necrotic+chlorotic, agreeing with previous observations that IA can be a more repeatable method for measuring disease $(25,26)$.

Lin's concordance correlation coefficient $\left(\rho_{c}\right)$ showed that the IA rating was more reproducible than repeats by VRs. IA estimates of lesion number (Fig. 3) returned a $\rho_{c}$ of $0.99(r=0.99)$. The estimate of $C_{b}$ was 1.00 , suggesting close to complete accuracy (no bias) due to locational $(\mu=0.004)$ or scale $(v=1.007)$ shifts. In contrast, VR3 had a $\rho_{c}$ of $0.76(r=0.89)$ and relatively large locational $(\mu, 0.266)$ and scale shifts $(v, 1.687)$ showing less good intra-rater repeatability. VR1 and VR2 were intermediate between VR3 and IA for repeatability of lesion numbers. All measures of severity based on estimates of diseased area were less precise or accurate than counts of lesion number, and measures by VRs were consistently less repeatable compared to IA. The $\rho_{c}$ of the repeat estimate of $\%$ area necrotic (Fig. 4) by IA was $0.96(r=0.96)$. The estimate of $C_{b}$ was 0.99 , and was both precise and accurate with little bias due to locational $(\mu=$ $0.034)$ or scale $(v=1.048)$ shifts. VRs showed a lower capacity to repeat previous estimates of $\%$ area necrotic $\left(\rho_{c}=0.72\right.$ to $0.84 ; r=0.74$ to 0.85 ), and had greater locational shifts $(\mu=-0.157$ to 0.219$)$ and scale shifts $(v=0.774$ to 1.050$)$ compared to IA. The repeat estimate of \% area necrotic+chlorotic (Fig. 5) by IA returned a $\rho_{c}$ of 0.97 ( $\left.r=0.97\right)$. The estimate of $C_{b}$ was 0.99 , suggesting very little bias due to locational $(\mu=-0.025)$ or scale $(v=0.972)$ shifts. VRs were less able to repeat previous estimates of $\%$ area necrotic+chlorotic ( $\rho_{c}=0.85$ to $0.88 ; r=0.86$ to 0.89 ), having larger locational $(\mu, 0.160$ to 0.154$)$ and scale shifts $(v, 0.755$ to 1.142$)$. However, repeat estimates of \% necrotic+chlorotic were more reproducible than estimates of $\%$ area necrotic.

These data show that repeat assessments by IA have the highest reproducibility, and reassessments are only relatively mildly flawed (Fig. 6). IA consistently had the best values of $r, \rho_{c}, C_{b}, \mu$, and $v$ for all symptom types assessed (lesion number, \% area necrotic, and \% area necrotic+ chlorotic) compared to VRs. Repeat assessments by VRs show less intra-rater repeatability and were more variable than IA. Lesion number appeared to be the most repeatable measure across raters (including IA), followed by $\%$ area necrotic+ chlorotic, and \% area necrotic being the least well repeated.

Precision and accuracy of visual raters and the relationship between the actual and estimated values. IA was taken as the actual value-it also demonstrably and consistently had the highest reproducibility. There was a consistently good correlation (Table 3) among all three VRs and IA for lesion number in assess- 
ments 1 ( $r=0.88$ to 0.94$)$ and $2(r=0.89$ to 0.94 ). Correlations (and therefore precision) were slightly less good for estimates of $\%$ area necrotic+chlorotic ( $r=0.87$ to $0.92)$, and poorest for $\%$ area necrotic $(r=$ 0.77 to 0.83 ), due to the greatest scatter in estimates. The regression analysis (Table 3) gave reasonable linear relationships for lesion number $\left(r^{2}=0.79\right.$ to 0.88$)$ and $\%$ area necrotic+chlorotic $\left(r^{2}=0.77\right.$ to 0.84$)$, but less so for $\%$ area necrotic $\left(r^{2}=0.59\right.$ to 0.70 ), again due to the lack of precision estimating this symptom type. The $C V$ were high for all measures of disease between IA and VRs ( $C V=40.3$ to 71.8$)$, demonstrating the error associated with the sample. The standard errors of the prediction tended to be fairly similar within each assessment type for VR1-3, with no single rater being radically different from another. Regression analysis also showed that the relationship between IA and the VR varied depending on the symptom type assessed.

Lin's concordance correlation analyses were comparable between assessment times and showed that counts of lesion numbers $\left(\rho_{c}=0.87\right.$ to 0.99 ; Fig. 7$)$ were more reproducible by visual raters than either $\%$ area necrotic $\left(\rho_{c}=0.67\right.$ to 0.78 ; Fig. 8) or $\%$ area necrotic+chlorotic $\left(\rho_{c}=\right.$ 0.82 to 0.92 ; Fig. 9). Loss of accuracy $\left(C_{b}\right)$, comprised of locational shift $(\mu)$ and scale shifts $(v)$, showed that estimates of lesion number and estimates of $\%$ area necrotic+chlorotic were less variable and showed less discrepancy than $\%$ area necrotic. VR2 was most consistent in accuracy and precision when estimating lesion number, while VR1 and VR3 varied more between assessments. For example, VR3 in assessment 1 was less precise $(r=0.88)$ than in assessment $2(r=0.94)$. However, the measure of $\rho_{c}$ was the same for both (0.87). The $C_{b}$ was 0.98 for assessment 1 and 0.93 for assessment 2, due to scale shift $(v)$ in assessment 2 being greater than in assessment 1 (1.419 and 0.847, respectively), as was the locational shift $(\mu, 0.178$ and -0.082 , respectively). Thus, error in assessment of lesion number by VR3 was due to reduced precision and reduced accuracy_precision being less in assessment 1 , and accuracy being lower in assessment 2 . There were also differences in accuracy of estimates of \% area necrotic between assessments 1 and 2; for example, VR3 estimates of \% area necrotic had a $C_{b}$ of 0.85 and 0.96 in assessment 1 and 2, respectively. This difference was due to larger scale and locational shifts in assessment 1 ( $\mu=0.461$ and $v=1.461$, respectively), while in assessment 2 it was only moderate ( $\mu=0.294$ and $v=1.078$, respectively). VR1 and VR2 also showed reduced accuracy and precision estimating \% area necrotic, but related well to IA for $\%$ area necrotic+chlorotic ( $\rho_{c}=0.96$ to 1.0$)$. VR3 showed good accuracy in assessment $1\left(C_{b}\right.$ $=0.98$ ) but slightly poorer accuracy in assessment $2\left(C_{b}=0.91\right)$, due to both greater locational $(\mu=0.325)$ and scale shifts $(v=1.353)$ in assessment 2 . These tests of reproducibility demonstrated that the precision and accuracy of the assessment varies between assessments and raters, although losses in precision were often greater and depended on the symptom type being assessed.

The GLM analysis between the first and second assessments by the VRs (against the true mean) to test for heterogeneity of regression showed that most visual estimates differed significantly in intercept and/or slope (Table 4). Only VR2 demonstrated no significant difference between assessments 1 and 2 for number of lesions or \% area necrotic; however, VR1 and VR3 demonstrated significant differences in both measures of disease, and all three VRs showed significant differences in estimates between assessment of $\%$ area necrotic+chlorotic. The data for $\%$ area necrotic are the most scattered (least reproducible), and this makes it more difficult to differentiate regression lines (due to the resulting large residual error; 32 to $40 \%$
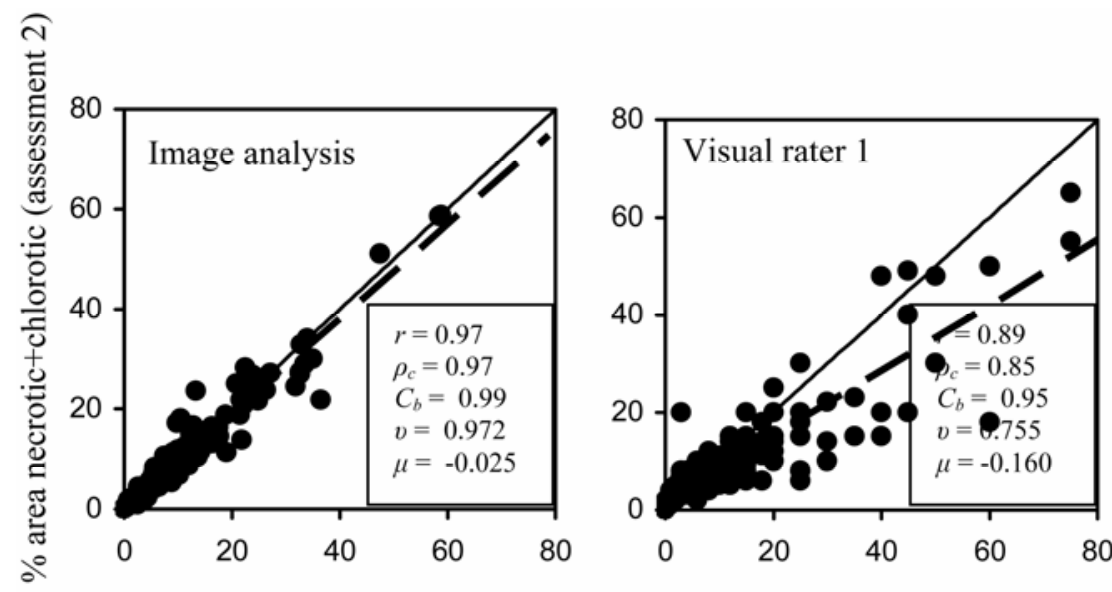

$\%$ area necrotic+chlorotic (assessment 1 )
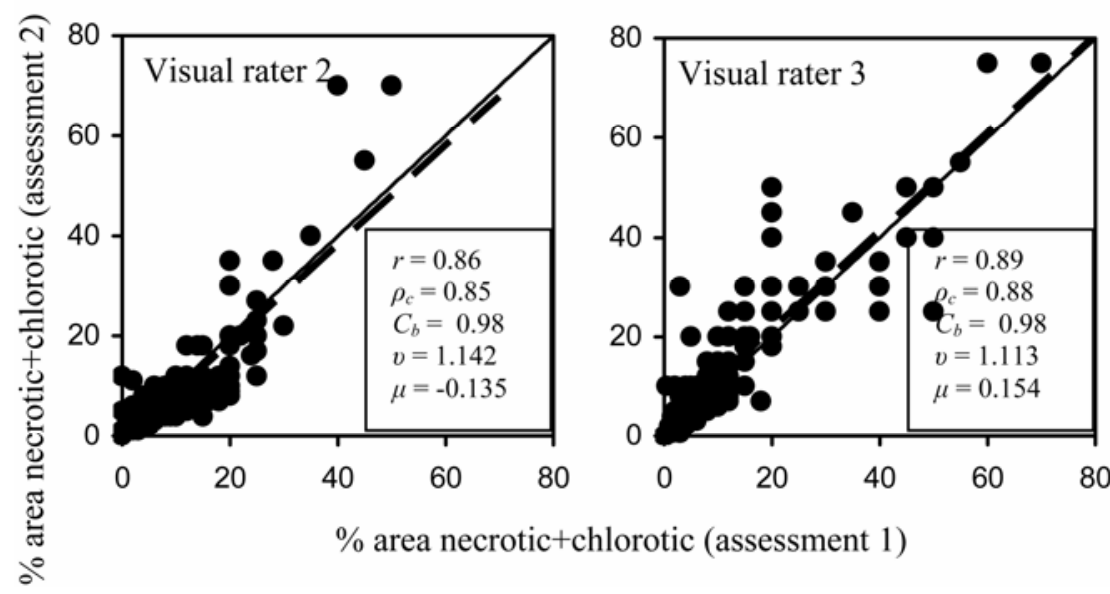

Fig. 5. A comparison of the $\%$ necrotic+chlorotic due to symptoms of citrus canker estimated on two separate assessment dates by image analysis and three visual raters. The concordance line is indicated by the solid line, and the broken line shows the actual relationship between the two assessments. Both measures of accuracy and precision are presented. The correlation coefficient, $r$, provides a measure of precision, and Lin's concordance correlation $\left(\rho_{c}\right)$ combines measures of precision $(r)$ and accuracy $\left(C_{b}\right)$, which is dependent on scale, or slope shift $(v, 1=$ no bias between $X$ and $Y)$, and location, or height shift ( $\mu, 0=$ no bias) relative to the concordance line. for $\%$ area necrotic $c f$. residual error of 14 to $23 \%$ for number of lesions and $\%$ area are taken as tacit approval that this method is highly reproducible - as already demonstrated earlier in this study, independen shown this to be the least reproducible symptom to assess.

Mean inter-rater reliability measured using correlation analysis (Table 5) was for both assessment 1 and 2 ) and least for $\%$ area necrotic (mean $r=0.79$ for both assessment 1 and 2). The inter-class correlations from ANOVA using a two-way a significant factor only for estimates of $\%$ area necrotic $(P<0.001$ and 0.016 for and 1 , respectively).

Among visual raters. Agreement among raters was tested by correlation and regression analysis (Table 6). sion lines for \% area necrotic should not be a com effects model showed that leaf was symptom types $(P<0.001)$, and rater was 

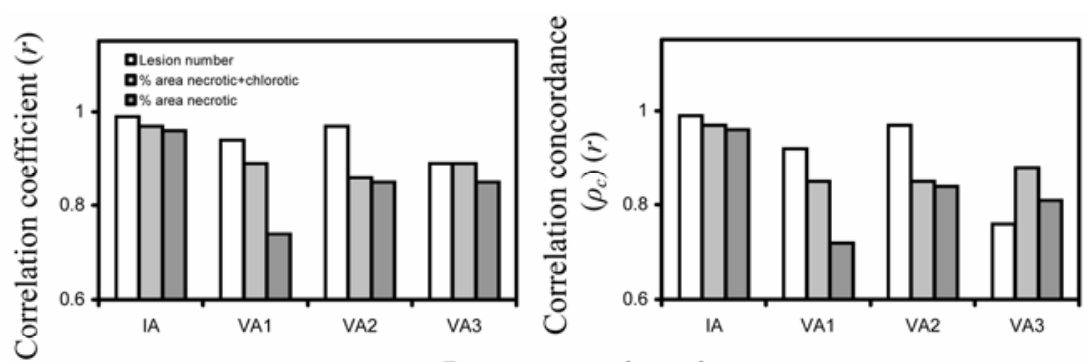

Rater type and number
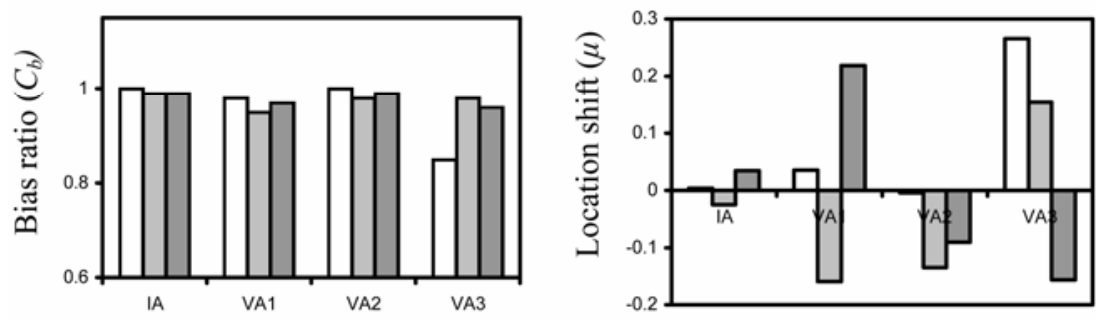

Rater type and number

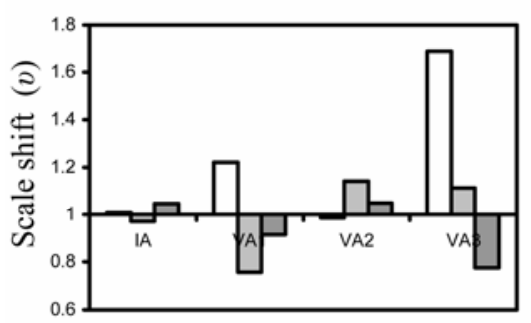

Rater type and number

Fig. 6. Comparison of measures of accuracy and precision for different symptom types of citrus canker on grapefruit leaves estimated by image analysis and three visual raters. The correlation coefficient, $r$, provides a measure of precision, and Lin's concordance correlation $\left(\rho_{c}\right)$ combines measures of precision $(r)$ and accuracy $\left(C_{b}\right)$, which is dependent on scale, or slope shift $(v, 1=$ no bias between $X$ and $Y$ ), and location, or height shift ( $\mu, 0=$ no bias) relative to the concordance line.
Correlations showed that the closest agreement was between raters for measures of lesion number ( $r=0.89$ to 0.98 ), an overlapping range for $\%$ area necrotic+chlorotic ( $r=0.85$ to 0.93 ), and least for $\%$ area necrotic ( $r=0.72$ to 0.81 ), demonstrating a level of reproducibility among VR1-3. Regression analysis showed a linear model described the relationship between all pairs of visual raters, and reproducibility was borne out by the regression analysis of lesion number $\left(r^{2}=0.83\right.$ to $0.95)$, followed by $\%$ area necrotic+ chlorotic $\left(r^{2}=0.72\right.$ to 0.87$)$ and $\%$ area necrotic $\left(r^{2}=0.51\right.$ to 0.69$)$, which had particularly low coefficients of determination, reflecting lower reproducibility. $C V \mathrm{~s}$ were variable among the comparisons for all symptoms $(C V=29.8$ to 74.3$)$, and standard errors of the prediction ranged from 4.0 to 8.7 for lesion number, 2.3 to 3.6 for $\%$ area necrotic, and 4.3 to 6.9 for $\%$ area necrotic+ chlorotic. The results show reasonable to good agreement among raters for lesion number and $\%$ area necrotic+chlorotic, but not for $\%$ area necrotic.

There was apparent clustering of ratings (e.g., 25, 30, 35, 40, etc.), particularly above $20 \%$ disease (Fig. 10). Raters were quite prepared to estimate disease below $1 \%$, and at $1 \%$ increments for both $\%$ area necrotic and \% area necrotic+chlorotic, until approximately 20\% (with a slight preference for 12 and 18 as intermediates between 10,15 , and 20 , above which they showed a marked tendency to estimate to the nearest $5 \%$.

Table 3. Linear regression analysis ${ }^{\mathrm{a}}$ of the first and second assessments by image analysis and three visual raters for number of lesions, \% leaf area necrotic and $\%$ leaf area necrotic+chlorotic

\begin{tabular}{|c|c|c|c|c|c|c|c|}
\hline \multirow{2}{*}{$\begin{array}{l}\begin{array}{l}\text { Variable } \\
\text { Assessment }\end{array} \\
\text { Number of lesions per leaf }\end{array}$} & \multirow[t]{2}{*}{ Comparison } & \multirow[t]{2}{*}{$r^{\mathbf{b}}$} & $\begin{array}{c}\text { Intercept }^{\mathbf{c}, \mathbf{d}} \\
\text { (standard error) }\end{array}$ & \multirow[t]{2}{*}{$\begin{array}{c}\text { Slope } \\
\text { (standard error) }\end{array}$} & \multirow[t]{2}{*}{$r^{2 \mathrm{e}}$} & \multirow[t]{2}{*}{$C V^{\mathrm{f}}$} & \multirow[t]{2}{*}{$S E^{\mathrm{g}}$} \\
\hline & & & & & & & \\
\hline \multirow[t]{3}{*}{ Assessment 1} & IA vs. VR1 & 0.94 & $(0.719)$ & $0.99 * * *(0.025)$ & 0.88 & 45.8 & 8.2 \\
\hline & IA vs. VR2 & 0.92 & $(0.859)$ & $0.10 * * *(0.030)$ & 0.85 & 54.4 & 9.8 \\
\hline & IA vs. VR3 & 0.88 & $2.83^{* * *}(0.819)$ & $0.75^{* * *}(0.029)$ & 0.78 & 56.9 & 9.4 \\
\hline \multirow[t]{3}{*}{ Assessment 2} & IA vs. VR1 & 0.89 & $-1.52 \quad(1.185)$ & $1.13 * * *(0.041)$ & 0.79 & 71.8 & 13.6 \\
\hline & IA vs. VR2 & 0.91 & $(0.878)$ & $0.97 * * *(0.030)$ & 0.83 & 56.0 & 10.1 \\
\hline & IA vs. VR3 & 0.94 & $(0.986)$ & $1.33 * * *(0.033)$ & 0.88 & 49.3 & 11.3 \\
\hline \multicolumn{8}{|l|}{$\%$ area necrotic } \\
\hline \multirow[t]{3}{*}{ Assessment 1} & IA vs. VR1 & 0.79 & $1.13 * * *(0.185)$ & $0.70 * * *(0.038)$ & 0.62 & 55.9 & 1.9 \\
\hline & IA vs. VR2 & 0.78 & $1.61 * * *(0.288)$ & $1.08 * * *(0.06)$ & 0.61 & 58.1 & 3.0 \\
\hline & IA vs. VR3 & 0.83 & $1.24 * * *(0.270)$ & $1.21 * * *(0.056)$ & 0.70 & 53.4 & 2.8 \\
\hline \multirow[t]{3}{*}{ Assessment 2} & IA vs. VR1 & 0.82 & $1.91 * * *(0.158)$ & $0.64 * * *(0.032)$ & 0.66 & 40.3 & 1.7 \\
\hline & IA vs. VR2 & 0.77 & $1.08 * * *(0.309)$ & $1.07 * * *(0.062)$ & 0.59 & 68.3 & 3.3 \\
\hline & IA vs. VR3 & 0.80 & $1.58 * * *(0.223)$ & $0.87 * * *(0.045)$ & 0.64 & 51.6 & 2.4 \\
\hline \multicolumn{8}{|c|}{$\%$ area necrotic + chlorotic } \\
\hline \multirow[t]{3}{*}{ Assessment 1} & IA vs. VR1 & 0.90 & $(0.524)$ & $1.16 * * *(0.039)$ & 0.81 & 52.7 & 5.6 \\
\hline & IA vs. VR2 & 0.88 & $2.06 * * *(0.375)$ & $0.74 * * *(0.028)$ & 0.77 & 46.0 & 4.0 \\
\hline & IA vs. VR3 & 0.92 & $0.77 \quad(0.445)$ & $1.08 * * *(0.033)$ & 0.84 & 44.8 & 4.9 \\
\hline \multirow[t]{3}{*}{ Assessment 2} & IA vs. VR1 & 0.87 & $1.11 * \quad(0.443)$ & $0.88 * * *(0.034)$ & 0.76 & 53.4 & 4.7 \\
\hline & IA vs. VR2 & 0.88 & $(0.428)$ & $0.87 * * *(0.033)$ & 0.77 & 61.0 & 4.6 \\
\hline & IA vs. VR3 & 0.90 & $1.53 * * \quad(0.540)$ & $1.21 * \quad(0.041)$ & 0.82 & 45.1 & 5.7 \\
\hline
\end{tabular}

${ }^{\mathrm{a}}$ Linear regression analysis model $y=a+b x$, where $a=$ intercept, and $b=$ slope.

${ }^{\mathrm{b}}$ Correlation coefficient measures the degree of association between raters.

$\mathrm{c} *, * *, * * *$, Probability $=0.05,0.01$, and 0.001 , respectively.

${ }^{\mathrm{d}}$ Significant deviation of the intercept from 0 indicates a positive or negative over- or under-estimate of the value, constituting a constant systematic error; significant deviation of the slope from 1.0 indicates proportional systematic error between assessments.

${ }^{\mathrm{e}}$ Coefficient of determination is a quantitative measure of precision (or agreement) between the two assessments - the degree to which the X-data explain the Y-data.

${ }^{\mathrm{f}}$ Coefficient of variation is a measure of repeatability (precision).

$\mathrm{g}$ Standard error of the estimate provides a measure of the difference between assessments, quantifying the random error. 


\section{DISCUSSION}

IA consistently returned the highest measures of repeatability between the first and second assessments, compared to any of the VRs. This was true for either citrus canker lesion number or measures of percent area with symptoms of citrus canker. IA showed the greater accuracy and removed much of the variability from the repeat estimates. IA was used as the actual value against which the visual raters were compared (each leaf was processed by an independent operator using the image analysis software and coalesced lesions individually separated and areas demarcated to minimize error). These data support several previous observations $(25,26)$ regarding the potential accuracy and precision of IA. However, it does contrast with the relatively poor reproducibility of IA in some other studies $(31,44)$. Differences among studies may be due in part to the unit of assessment-most studies used individual leaf images, whereas Nutter et al. (30) were assessing $1 \mathrm{~m}^{2}$ quadrats of diseased vegetation, and in part to the degree to which each image was checked for accuracy of coverage during the IA process, which would influence how reproducible the results were, as colors and other lesion characteristics do vary among leaf images affecting demarcation of lesion boundaries between samples. For IA to offer greatest benefit, each leaf should not have to be checked visually for the demarking of infected areas, but this would probably increase variability due to leaf-toleaf differences (31), although Martin and Rybicki (26) found highly reproducible results with an automated IA system that was at least as accurate as the IA operator. The IA operator can affect estimates whenever these parameters are reset for different images. However, this source of error is present wherever an operator is creating a true standard by having to establish where a diseased area begins or ends including when using ink and acetate sheets (31) or cutting out specific image areas (28). Comparing the first and second VRs against the IA standards using GLM for each symptom type showed significant differences between assessments for VR13 . The $\%$ area necrotic+chlorotic was significantly different between assessments for all raters, but raters for other symptom types were inconsistent. This runs somewhat counter to the other measures of reproducibility, as \% area necrotic was consistently the least reproducible based on all other measures. The scattered (imprecise) nature of these data resulted in generally large residual errors (32 to $40 \%$ ) and thus less opportunity to detect significance. Conversely, the counts of lesions and the $\%$ area necrotic+chlorotic had smaller residual errors (14 to $23 \%$ ), and thus detecting differences would be somewhat more sensitive. However, it should be stressed that there is also the possibility that a very reproducible method (e.g., lesion numbers) could also result in rejection of a highly reproducible result due to particularly small residual errors. For these reasons, tests of heterogeneity of regression should be treated with caution if they are used to compare methods or repeatability.

There was inter-rater variability among VRs in ability to accurately and precisely assess different symptom types. However, it is not surprising that counts of lesion numbers were most reproducible; it is surprising that lesion numbers were as variable as they were considering that it should be a straightforward count. Severity of $\%$ area necrotic+chlorotic was estimated less well, and \% area necrotic was least well estimated. These observations were borne out by the various tests for precision

\section{First assessment}

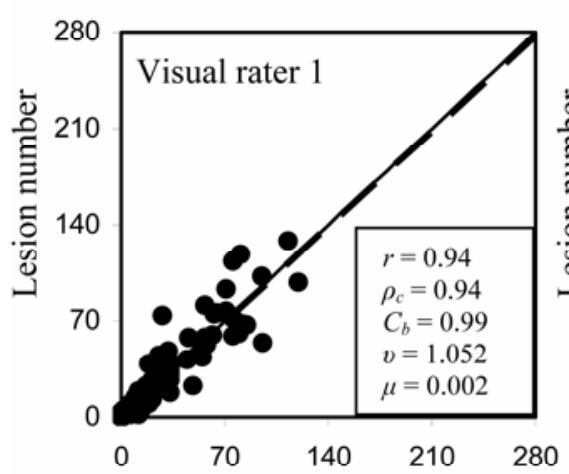

Second assessment

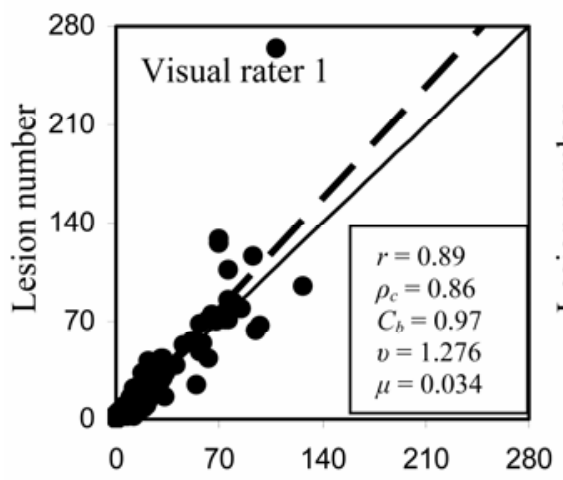

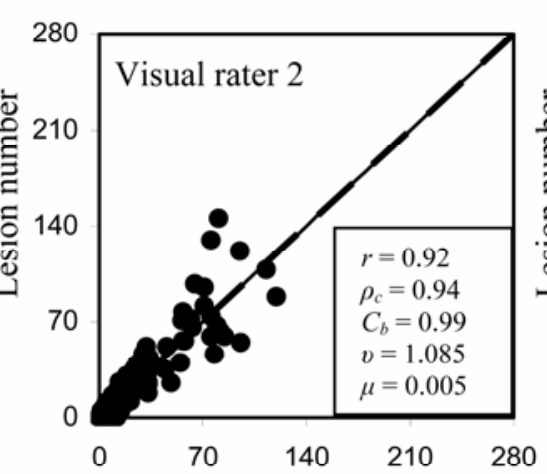

Lesion number (image analysis)
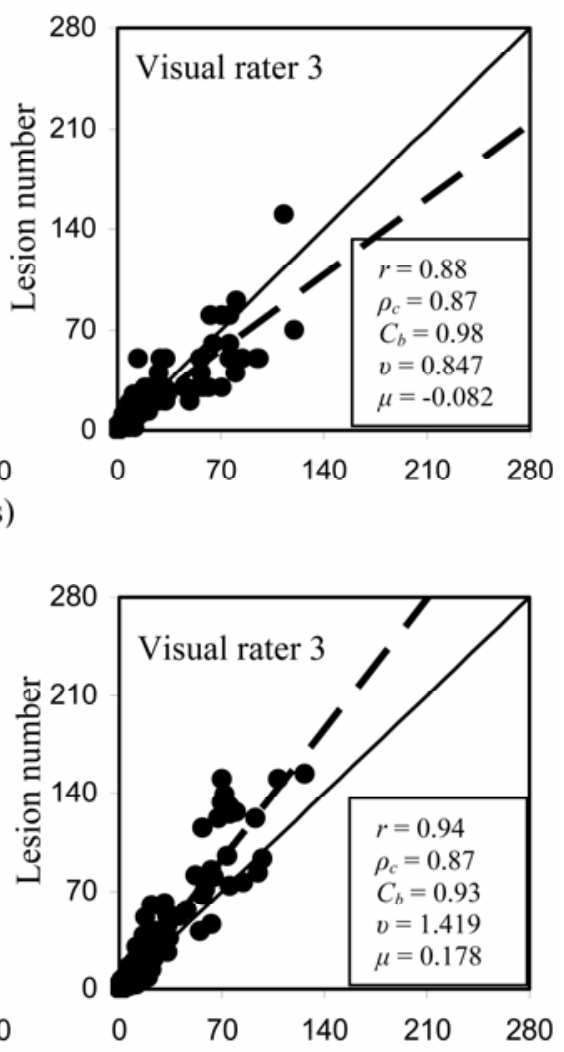

Lesion number (image analysis)

Fig. 7. The accuracy and precision of estimates of lesion numbers of citrus canker on two separate assessment dates by three visual raters (compared to the true values). The concordance line is indicated by the solid line, and the broken line shows the actual relationship between the two assessments. Both measures of accuracy and precision are presented. The correlation coefficient, $r$, provides a measure of precision, and Lin's concordance correlation $\left(\rho_{c}\right)$ combines both measures of precision $(r)$ and accuracy $\left(C_{b}\right)$, which is dependent on scale, or slope shift $(v$, $1=$ no bias between $X$ and $Y$ ), and location, or height shift ( $\mu, 0=$ no bias) relative to the concordance line. 
$\left(r, C V, S E, r^{2}\right)$ and accuracy $\left(\rho_{c}, C_{b}, \mu, v\right)$ that were used, and the observations on inter-rater variation are similar to those previously reported for measures of disease severity $(28,31)$, although the $C V$ reported here tends to be greater. Correlations among pairs of raters (inter-rater reliability) were highest for measures of lesion number and \% area necrotic+ chlorotic, and similar to estimates obtained for inter-rater reliability for Phomopsis leaf blight on strawberry (28), with $\%$ area necrotic being least precisely estimated. Furthermore, the estimates of inter-rater reliability using ANOVA $(\rho)$, apart from showing that leaf was a significant factor for all estimates of disease, showed that rater was significant for measures of $\%$ area necrotic. Thus, despite variation, the three raters showed reasonable reproducibility for estimates of lesion number and \% area necrotic+chlorotic. Characteristics of symptoms (texture, lesion numbers, and size, color, age, etc.) may all influence the ability to assess accurately and precisely, particularly if dealing with lesion parts such as $\%$ area necrotic. Indeed, some symptoms or plant structures can have a direct influence on estimations of severity, biasing the result $(1,2,10,39)$, although that was not tested in this study.

The level of accuracy and preciseness among VRs when assessing percent area infected with citrus canker would probably be improved by the use of disease assessment cards. With lesion numbers, of course, this is not an issue, but for estimates of area, assessment cards are known to improve the accuracy and precision (and therefore reproducibility) of disease estimates $(19,22,30,32)$. A set of disease assessment diagrams has been developed for citrus canker and was found to improve estimation of canker severity (4). Estimation of disease is also improved by performing assessment training that can be computer-based $(32,36)$. Although VRs had the lowest reproducibility compared to IA, errors in IA also existed and could stem from the system's inability to differentiate between coalesced lesions, which is likely to be an increasing source of error as severity and lesion numbers increase, resulting in underestimates of lesion numbers. VRs are better equipped to count lesions when this source of errors exists, but the data clearly demonstrate that VRs exhibit greater variability in recounting.

There was a linear relationship between the VR estimates of citrus canker severity and the actual disease. This is in agreement with previous observations of a linear relationship between estimates and actual disease $(15,26,28,29,31,39)$. Several of these reports assumed that Horsfall and Barratt (17) applied the Weber-Fechner law as meaning that there was a logarithmic relationship between actual disease and estimated disease (one increase in perceived disease on the $Y$-axis is equal to a logarithmic increase on the $X$-axis, or an arithmetic increase in the perceived disease is accompanied by a geometric increase in the actual disease). Indeed, the WeberFechner law is no longer thought to hold true for many stimuli $(3,42)$ and perhaps not for perception of plant diseases $(15,28,29)$. The linear relationship was consistent over the range of citrus canker severity and lesion numbers assessed in this study, and there was no noticeable consistent under-estimate of disease by VRs as actual disease severity increased as would be expected if a logarithmic rela-

\section{First assessment}

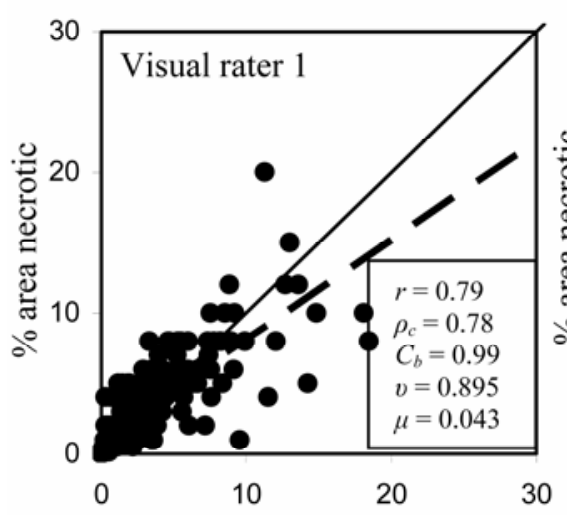

Second assessment
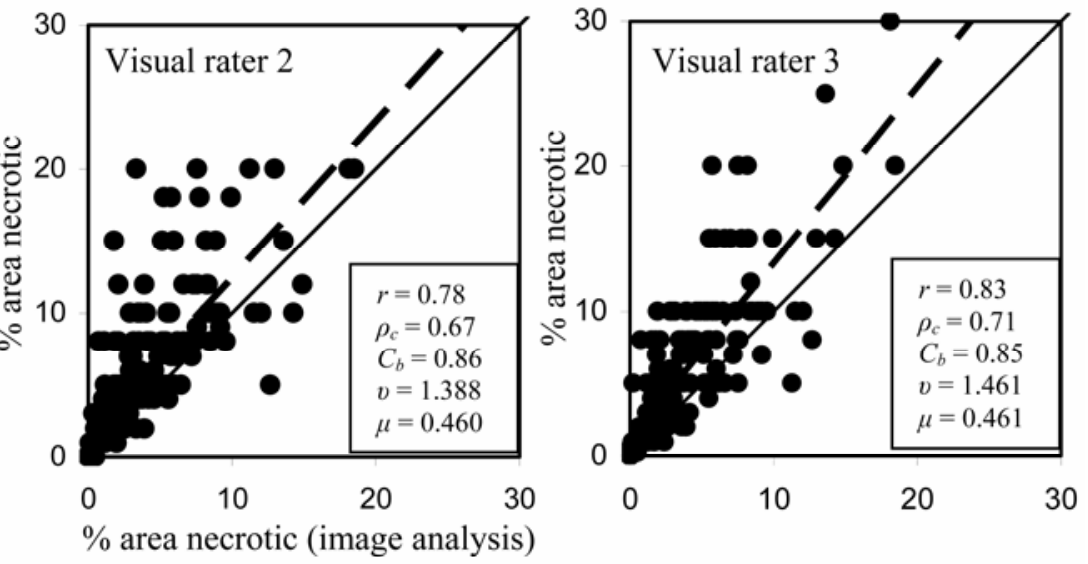

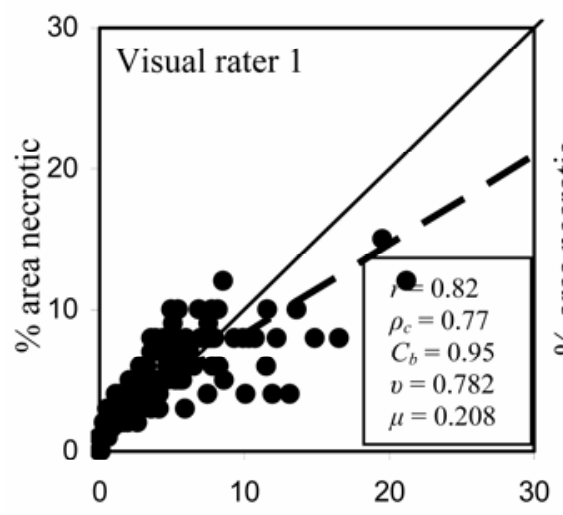

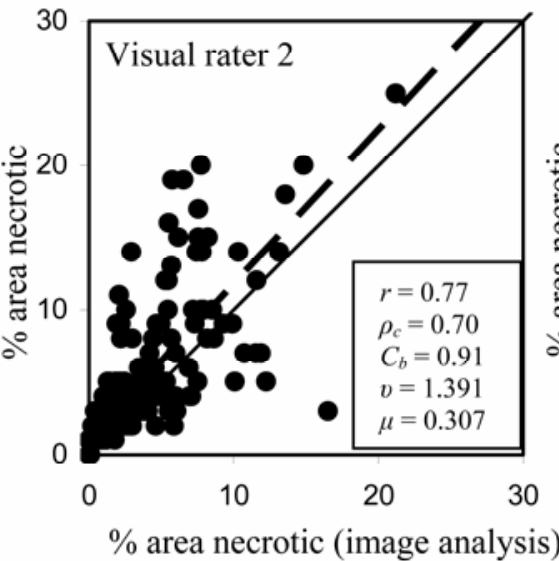

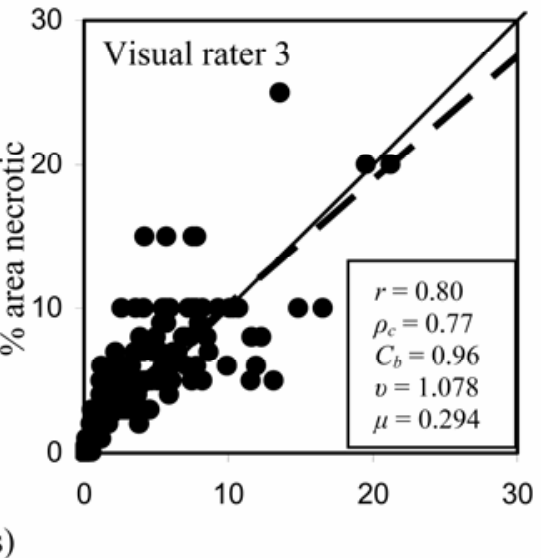

Fig. 8. The accuracy and precision of estimates of \% area necrotic due to citrus canker on two separate assessment dates by three visual raters (compared to the true values). The concordance line is indicated by the solid line, and the broken line shows the actual relationship between the two assessments. Both measures of accuracy and precision are presented. The correlation coefficient, $r$, provides a measure of precision, and Lin's concordance correlation $\left(\rho_{c}\right)$ combines both measures of precision $(r)$ and accuracy $\left(C_{b}\right)$, which is dependent on scale, or slope shift $(v$, $1=$ no bias between $X$ and $Y)$, and location, or height shift ( $\mu, 0=$ no bias) relative to the concordance line. 
tionship existed. However, it was noted that at disease levels above $20 \%$, the VRs tended to prefer to categorize disease to the nearest $5 \%(25,30,35,40$, etc.). This tendency to form "knots" has been noted before (20), and may reflect a rater's lack of ability to assess disease accurately and precisely in the midrange of severity. Others report greater accuracy and precision below $20 \%$ disease and above $80 \%$, but the relationship(s) remains elusive $(10,20,33)$. Several studies have questioned the HB scale, as it appears to offer no advantages over direct estimation or alternative scales $(10,28,33,39)$, and Nutter and Esker (29), using the psychophysical method of threshold differences (and the just noticeable difference [jnd]), tested three disease severity levels $(25,37$, and $50 \%)$ and did not detect any difference in ability to estimate the disease, concluding that an additional category could be incorporated in the HB scale between 25 and 50\% based on the jnd. However, they did not report whether disease $<25 \%$ (or $>50 \%$ ) is as accurately and precisely estimated as 25 to $50 \%$. Variance in disease estimation generally appears to be greater in the midrange compared to very low or very high disease $(10,14,33)$. If the linear relationship be- tween estimated and actual disease is based on data that are heteroscedastic, then the assumptions of the regression may be violated, as the variances will be over- or under-stated (and thus the standard errors of the model parameters), thereby negating the value of the $t$ test, at least in the absence of appropriate transformations-another reason for treating the slope and intercept with caution. Further research is needed to unravel the relationships across the full range of disease severities.

Image analysis does offer several advantages. It is easy to use and is comparatively inexpensive-it permits building a library of digital images, sampling nondestructively (and resampling), and as there is an image, double-checking. Citrus leaves can remain on a plant for many months (43), and thus repeated measures of canker severity and symptom progress can be made.

Table 4. Results of a general linear modeling (GLM) analysis to test for heterogeneity of regression between visual assessment during the first and second assessments (all data)

\begin{tabular}{|c|c|c|c|c|}
\hline \multirow{2}{*}{$\begin{array}{c}\text { Variable } \\
\text { Rater }\end{array}$} & \multicolumn{2}{|c|}{ Test of parallelism } & \multicolumn{2}{|c|}{ Test of intercept } \\
\hline & $F$ value & $P$ value & $F$ value & $P$ value \\
\hline \multicolumn{5}{|c|}{ Number of lesions per leaf } \\
\hline VR1 & 9.2 & $0.0026^{a}$ & 0.7 & 0.402 \\
\hline VR2 & 0.5 & 0.492 & 0.0 & 0.921 \\
\hline VR3 & 171.5 & $<0.0001$ & 30.8 & $<0.0001$ \\
\hline \multicolumn{5}{|c|}{$\%$ area necrotic } \\
\hline VR1 & 1.8 & 0.179 & 13.7 & 0.0002 \\
\hline VR2 & 0.0 & 0.866 & 2.1 & 0.147 \\
\hline VR3 & 23.5 & $<0.0001$ & 7.3 & 0.007 \\
\hline \multicolumn{5}{|c|}{$\%$ area necrotic+chlorotic } \\
\hline VR1 & 30.7 & $<0.0001$ & 2.1 & 0.15 \\
\hline VR2 & 9.0 & 0.0029 & 8.2 & 0.004 \\
\hline VR3 & 6.5 & 0.0115 & 13.8 & 0.0002 \\
\hline
\end{tabular}

${ }^{a}$ Bold type indicates a significant difference.

\section{First assessment}
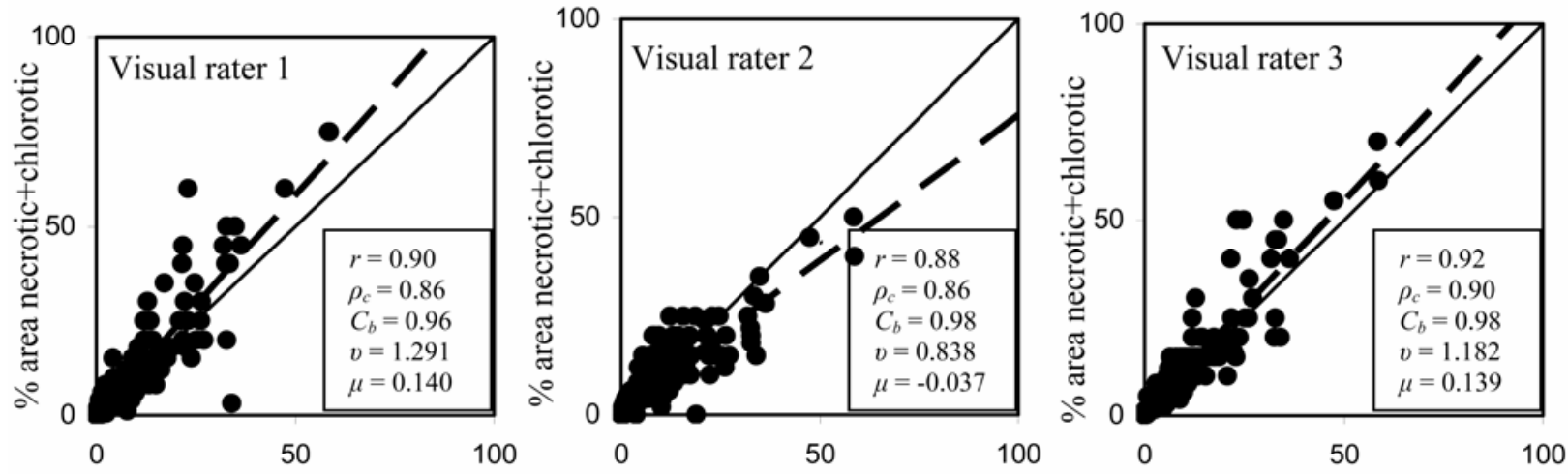

Second assessment

$\%$ area necrotic + chlorotic (image analysis)
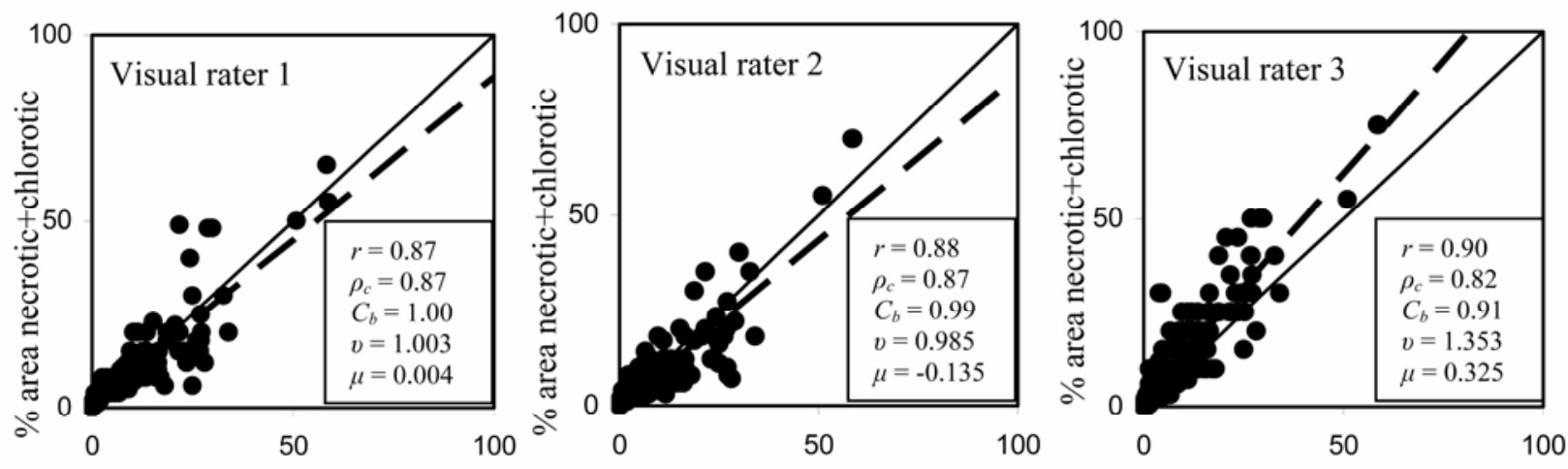

$\%$ area necrotic + chlorotic (image analysis)

Fig. 9. The accuracy and precision of estimates of \% area necrotic+chlorotic due to citrus canker on two separate assessment dates by three visual raters (compared to the true values). The concordance line is indicated by the solid line, and the broken line shows the actual relationship between the two assessments. Both measures of accuracy and precision are presented. The correlation coefficient, $r$, provides a measure of precision, and Lin's concordance correlation $\left(\rho_{c}\right)$ combines measures of precision $(r)$ and accuracy $\left(C_{b}\right)$, which is dependent on scale, or slope shift $(v, 1=$ no bias between $X$ and $Y)$, and location, or height shift $(\mu, 0=$ no bias) relative to the concordance line. 
Table 5. Inter-rater reliability of visual assessments of different symptoms of severity of citrus canker on grapefruit leaves on two assessment occasions

\begin{tabular}{|c|c|c|c|c|}
\hline \multirow[b]{2}{*}{ Variable } & \multicolumn{2}{|c|}{$\begin{array}{l}\text { Mean pair-wise inter-rater } \\
\text { correlation }(r)^{\mathrm{a}}\end{array}$} & \multicolumn{2}{|c|}{ Intra-class correlation $(\rho)^{b}$} \\
\hline & Assessment 1 & Assessment 2 & Assessment 1 & Assessment 2 \\
\hline Number of lesions per leaf (log) & 0.92 & 0.92 & $\begin{array}{l}0.99 \\
P>F: \\
\text { Leaf number }=<0.001 \\
\text { Rater }=0.799\end{array}$ & $\begin{array}{l}0.99 \\
P>F: \\
\text { Leaf number }=<0.001 \\
\quad \text { Rater }=0.807\end{array}$ \\
\hline$\%$ area necrotic (angular transformation) & 0.79 & 0.79 & $\begin{array}{l}0.91 \\
P>F: \\
\quad \text { Leaf number }=<0.001 \\
\quad \text { Rater }=<0.001\end{array}$ & $\begin{array}{l}0.95 \\
P>F: \\
\quad \text { Leaf number }=<0.001 \\
\quad \text { Rater }=0.016\end{array}$ \\
\hline$\%$ area necrotic + chlorotic (angular transformation) & 0.89 & 0.88 & $\begin{array}{l}0.98 \\
P>F: \\
\text { Leaf number }=<0.001 \\
\text { Rater }=0.225\end{array}$ & $\begin{array}{l}0.97 \\
P>F: \\
\quad \text { Leaf number }=<0.001 \\
\text { Rater }=0.089\end{array}$ \\
\hline
\end{tabular}

a Mean correlation coefficients estimated from assessments by all visual raters.

${ }^{\mathrm{b}}$ Intra-class correlation estimated by ANOVA, data for lesion numbers log transformed, and for \% area necrotic and \% area necrotic+chlorotic, angular transformed prior to analysis.

Table 6. Linear regression analysis ${ }^{\mathrm{a}}$ comparing the visual raters in the first and second assessments for number of lesions, $\%$ leaf area necrotic, and $\%$ leaf area necrotic+chlorotic

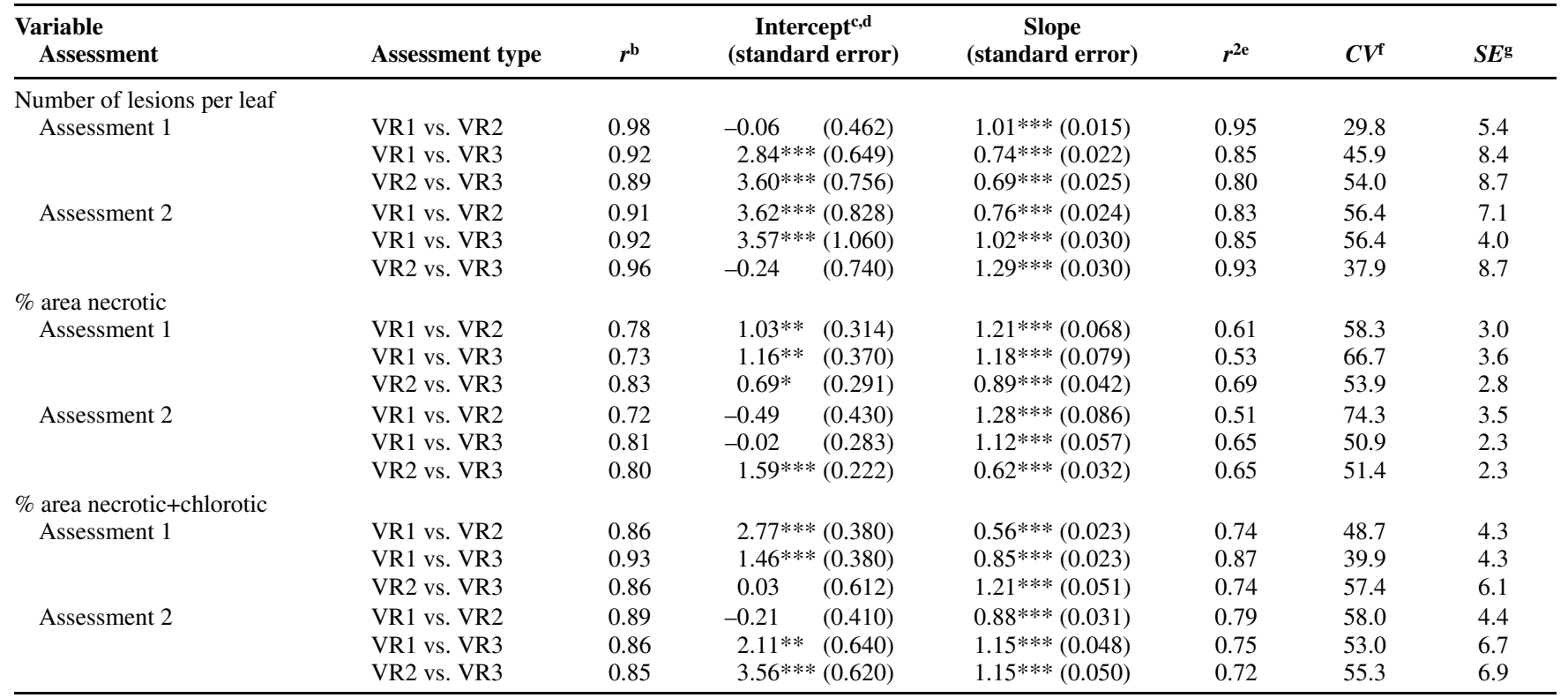

a Linear regression analysis model $y=a+b x$, where $a=$ intercept, and $b=$ slope.

$\mathrm{b}$ Correlation coefficient measures the degree of association between raters.

$\mathrm{c} *, * *, * * *$, Probability $=0.05,0.01$, and 0.001 , respectively.

${ }^{\mathrm{d}}$ Significant deviation of the intercept from 0 indicates a positive or negative over- or under-estimate of the value, constituting a constant systematic error; significant deviation of the slope from 1.0 indicates proportional systematic error between assessments.

e Coefficient of determination is a quantitative measure of precision (or agreement) between the two assessments-the degree to which the X-data explain the Y-data.

${ }^{\mathrm{f}}$ Coefficient of variation is a measure of repeatability (precision).

g Standard error of the estimate provides a measure of the difference between assessments, quantifying the random error.

It can provide more uniformity and objectivity in disease assessment, but does not have the ability to discriminate heterogeneous or complex symptoms. Other drawbacks could include the presence of multiple diseases on the same leaf (some form of artificial intelligence may be required to differentiate these) and the speed at which samples can be processed. There is also the potentially compounding effect of leaf miner damage, which can exacerbate and alter canker symptoms and may make them less amenable to image analysis. Lesions associated with leaf miner damage were not examined in this study. If greater automation can be achieved, then time savings could be substantial (26). Neither image analysis nor radiometric approaches $(27,31)$ appear to have been widely used in plant disease assessment to date, but they would both appear to have a lot of potential. In conclusion, IA has the potential to be a useful tool for assessing images of citrus canker both accurately and precisely, but greater automation (without loss in reproducibility between leaves) is needed to make this practical; until such time it is likely to remain in relatively narrow use where high levels of accuracy are required.
LITERATURE CITED

1. Agostini, J. P., Graham, J. H., and Timmer, L. W. 1985. Relationship between development of citrus canker and rootstock cultivar for young "Valencia" orange trees in Misiones, Argentina. Proc. Fla. State Hortic. Soc. 98:1922

2. Amanat, P. 1976. Stimuli effecting disease assessment. Agric. Conspectus Sci. 39:27-31.

3. Baird, J. C., and Noma, E. 1978. Fundamentals of scaling and psychophysics. Wiley, New York.

4. Belasque Junior, J., Bassanezi, R. B., Spósito, M. B., Ribeiro, L. M., de Jesus Júnior, W. C., and Amorim, L. 2005. Escalas diagramáticas para avaliação da severidade do cancro cítrico. Fitopatol. Bras. 30:387-393.

5. Bock, C. H., Parker, P. E., Cook, A. Z., and 
$\%$ area necrotic

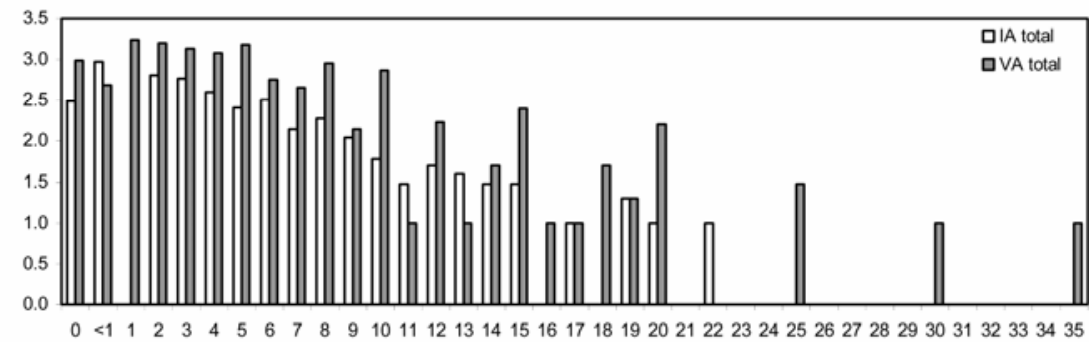

\section{$\%$ area necrotic + chlorotic}
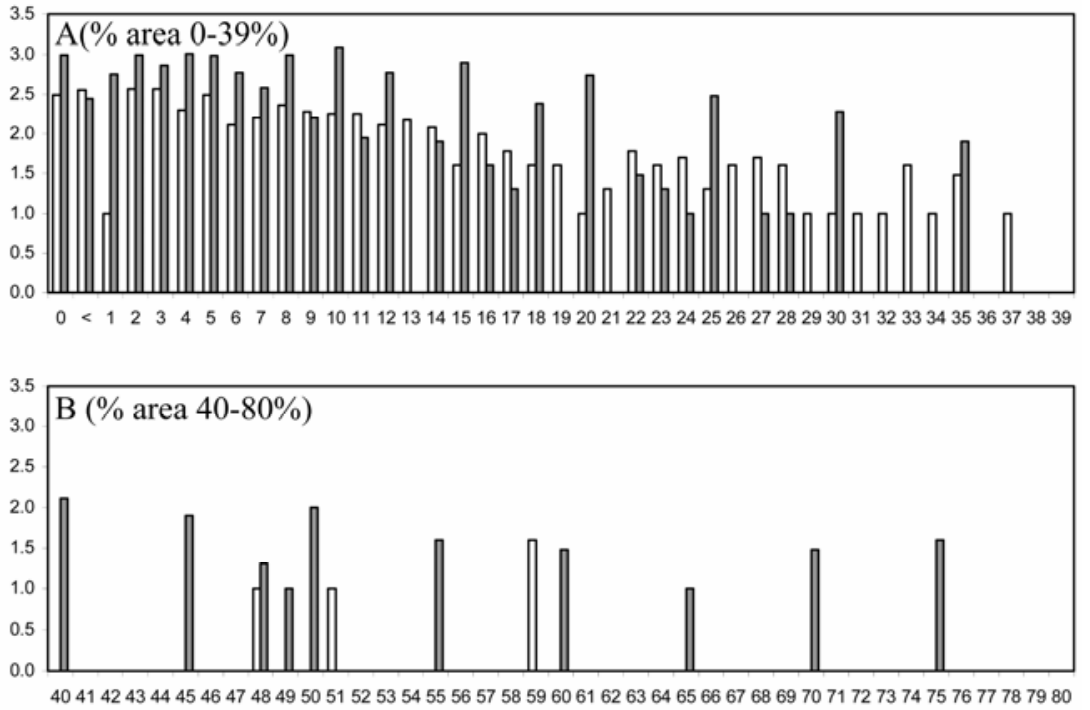

Fig. 10. Counts of assessment values (log transformed) of the \% area necrotic and the $\%$ area necrotic+chlorotic estimated by visual raters compared to the true value of disease (measured by image analysis). Image analysis is rounded to the nearest percent except for the category $<1 \%$.

Gottwald, T. R. 2006. Factors affecting infection of citrus with Xanthomonas axonopodis pv. citri. (Abstr.) Phytopathology 96:S14.

6. Bock, C. H., Parker, P. E., and Gottwald, T. R. 2005. The effect of simulated wind-driven rain on duration and distance of dispersal of Xanthomonas axonopodis pv. citri from canker infected citrus trees. Plant Dis. 89:71-80.

7. Campbell, C. L., and Madden, L. V. 1990. Introduction to Plant Disease Epidemiology. John Wiley \& Sons, New York.

8. Corkidi, G., Balderas-Ruiz, K. A., Taboada, B., Serrano-Carreon, L., and Galindo, E. 2006. Assessing mango anthracnose using a new three-dimensional image-analysis technique to quantify lesions on the fruit. Plant Pathol. 55:250-257.

9. Deinelt, M. M., and Lawson, R. H. 1989. Histopathology of Xanthomonas campestris pv. citri from Florida and Mexico in wound-inoculated detached leaves of Citrus aurantifolia: Transmission electron microscopy. Phytopathology 79:336-348.

10. Forbes, G. A., and Jeger, M. J. 1987. Factors affecting the estimation of disease intensity in simulated plant structures. Z. Pflkrankh. Pflschutz. 94:113-120.

11. Forbes, G. A., and Korva, J. T. 1994. The effect of using a Horsfall-Barratt scale on precision and accuracy of visual estimation of potato late blight severity in the field. Plant Pathol. 43:675-682.

12. Gottwald, T. R., and Graham, J. H. 1992. A device for precise and nondisruptive stomatal inoculation of leaf tissue with bacterial pathogens. Phytopathology 82:930-935.

13. Gottwald, T. R., and Irey, M. 2007. Post-hurricane analysis of citrus canker II: Predictive model estimation of disease spread and area potentially impacted by various eradication protocols following catastrophic weather events. Online feature. Plant Health Progress.

14. Hau, B., Kranz, J., and Konig, R. 1989. Fehler beim Schätzen von Befallsstärken bei Pflanzenkrankheiten. Z. Pflkrankh. Pflschutz. 96:649-674.

15. Herbert, T. T. 1982. The rationale for the Horsfall-Barratt plant disease assessment scale. Phytopathology 72:1269.

16. Horsfall, J. G. 1945. Fungicides and their action. Annales cryptogamica et phytopathologici, Vol II. Chronica Botanica, Waltham, MA.

17. Horsfall, J. G., and Barratt, R. W. 1945. An improved grading system for measuring plant disease. (Abstr.) Phytopathology 35:655.

18. Horsfall, J. G., and Cowling, E. B. 1978. Pathometry: The measurement of plant disease. Pages 120-136 in: Plant Disease: An Advanced Treatise Vol. II. J. G. Horsfall and E. B. Cowling, eds. Academic Press, New York.

19. James, W. C. 1971. An illustrated series of assessment keys for plant diseases, their preparation and usage. Can. Plant Dis. Surv. 51:39-65.

20. Koch, H., and Hau, B. 1980. Ein psychologischer aspect beim schatzen von pflanzenkrankheiten. Z. Pflkrankh. Pflschutz. 87:587-593.

21. Koizumi, M. 1976. Behavior of Xanthomonas citri (Hasse) Dowson in the infection process I. Multiplication of the bacteria and histological changes following needle prick inoculation. Ann. Phytopathol. Soc. Jpn. 42:407-416.

22. Kranz, J. 1988. Measuring plant disease. Pages 35-50 in: Experimental Techniques in Plant Disease Epidemiology. J. Kranz and J. Rotem, eds. Springer-Verlag, New York.

23. Lin, L. I.-K. 1989. A concordance correlation coefficient to evaluate reproducibility. Biometrics 45:255-268.

24. Lin, L. I.-K. 2000. A note on the concordance correlation coefficient. Biometrics 56:324-325.

25. Lindow, S. E., and Webb, R. R. 1983. Quantification of foliar disease symptoms by microcomputer-digitized video image analysis. Phytopathology 73:520-524.

26. Martin, D. P., and Rybicki, E. P. 1998. Microcomputer-based quantification of maize streak virus symptoms in Zea mays. Phytopathology 88:422-427.

27. Nilsson, H. E. 1995. Remote sensing and image analysis in plant pathology. Annu. Rev. Phytopathol. 15:489-527.

28. Nita, M., Ellis, M. A., and Madden, L. V. 2003. Reliability and accuracy of visual estimation of Phomopsis leaf blight of strawberry. Phytopathology 93:995-1005

29. Nutter, F. W., Jr., and Esker, P. D. 2006. The role of psychophysics in phytopathology. Eur. J. Plant Pathol. 114:199-213.

30. Nutter, F. W., Jr., Esker, P. D., and Coelho Netto, R. A. 2006. Disease assessment concepts in plant pathology and the advancements made in improving the accuracy and precision of plant disease data. Eur. J. Plant Pathol. 115:95-103.

31. Nutter, F. W., Jr., Gleason, M. L., Jenco, J. H. and Christians, N. C. 1993. Assessing the accuracy, intra-rater repeatability, and inter-rater reliability of disease assessment system. Phytopathology 83:806-812

32. Nutter, F. W. Jr, and Schultz, P. M. 1995 Improving the accuracy and precision of disease assessment: Selection of methods and use of computer-aided training programs. Can. J. Plant Pathol. 17:174-178.

33. O'Brien, R. D., and van Bruggen, A. H. C 1992. Accuracy, precision, and correlation to yield loss of disease severity scales for corky root of lettuce. Phytopathology 82:275-284.

34. Olmstead, J. W., and Lang, G. A. 2001. Assessment of powdery mildew infection of sweet cherry leaves by digital image analysis. HortScience 36:107-111.

35. Parker, P. E., Bock, C. H., and Gottwald, T. R. 2004. Citrus canker symptom assessment using image analysis. (Abstr.) Phytopathology 94:S81.

36. Parker, S. R., Whelan, M. J., and Royle, D. J. 1995. Reliable measurement of disease severity. Asp. App. Biol. 43:205-214.

37. Pruvost, O., Boher, B., Brocherieux, N. M. and Chiroleu, F. 2002. Survival of Xanthomonas axonopodis pv. citri in leaf lesions under ropical environmental conditions and simulated splash dispersal of inoculum. Phytopathology 92:336-346.

38. Schubert, T. S., Gottwald, T. R., Rizvi, S. A., Graham, J. H., Sun, X., and Dixon, W. N 2001. Meeting the challenge of eradicating citrus canker in Florida - again. Plant Dis. 85:340-356.

39. Sherwood, R. T., Berg, C. C., Hoover, M. R., and Zeiders, K. E. 1983. Illusions in visual assessment of Staganospora leaf spot of orchardgrass. Phytopathology 73:173-177.

40. Steddom, K., McMullen, M., Schatz, B., and Rush, C. M. 2005. Comparing image forma and resolution for assessment of foliar disease of wheat. Online. Plant Health Progress doi:10.1094/PHP-2005-0516-01-RS

41. Stevens, S. S. 1936. Psychology: The propaedeutic science. Phil. Sci. 3:90-103.

42. Stevens, S. S. 1961. To honor Fechner and repeal his law. Science 133:80-86.

43. Timmer, L. W., Garnsey, S. M., and Graham, J. H. 2000. Compendium of Citrus Diseases. American Phytopathological Society, St. Paul, MN.

44. Tucker, C. C., and Chakraborty, S. 1997. Quantitative assessment of lesion characteristics and disease severity using digital image processing. J. Phytopathol. 145:273-278. 